\title{
Cents of self: How and when self-signals influence consumer value derived from choices of green products
}

\author{
Accepted for Publication in: International Journal of Research in Marketing
}

Darcie Dixon and Sven Mikolon

\begin{abstract}
Consumers choosing between green and conventional products often believe such choices imply trade-off decisions, such that green products provide morally-related advantages but embody price or quality-related disadvantages compared to standard products. We study the con- sequences of such trade-offs for consumer value in the context of privately consumed green products. To develop our theoretical model, we draw from the perspective of selfsignaling - consumers' act of signaling information about their internal qualities to their own self through choice. We explore how and when self-signals from such trade-off decisions influence consumer value gained from comparative choices of green versus standard products. Six studies were conducted, using divergent measures of the dependent variable, multiple product categories, and measured as well as manipulated self-concept clarity (SCC). We find a joint effect of self-signals from comparative choices and self-concept clarity on consumer value, such that positive self-signals lead to incrementally higher satisfaction and willingness to pay for consumers with low SCC but not significantly so for those with high SCC. Results show that this joint effect may occur for consumers with low SCC because they gain incremental value from perceived self-concept alignment - a state that is construed from the perception that a self- signal is aligned with the consumer's self-concept. This study contributes to marketing research by proposing and testing a novel mechanism that can underlie self-signaling.
\end{abstract}


Consumers often have the lay belief that green products $^{1}$ provide morally-related benefits, such as being more environmentally friendly or less cruel to animals, but are less effective, are of lower quality, or are at a higher price than equivalent standard products (Alwitt \& Pitts, 1996; Carrington, Neville, \& Whitwell, 2014; Gleim, Smith, Andrews, \& Cronin, 2013; Green \& Peloza, 2014; Hughner, McDonagh, Prothero, Shultz, \& Stanton, 2007; Kidwell, Farmer, \& Hardesty, 2013; Magnusson, Arvola, Hursti, Åberg, \& Sjödén, 2003; McEachern \& McClean, 2002; Newholm \& Shaw, 2007; Steg \& De Groot, 2012). Thus, when choosing between green and standard products, consumers typically feel that they are forced to make a trade-off between conflicting motives, i.e., to choose quality or lower price over environmental friendliness, animal welfare, lack of harmful chemicals, or vice versa.

Yet, despite actual or perceived quality disadvantages, and hence lower functional utility, extant research suggests that consumers nonetheless can derive positive marginal utility from choices of green products (Carrington et al., 2014; Hughner et al., 2007; Magnusson et al., 2003). This utility often stems from other-image benefits, such as signaling status to others, a form of conspicuous consumption (Griskevicius, Tybur, \& Van Den Bergh, 2010; Guthman, 2002), or adopting environmentally friendly or sustain- able innovations to signal positive characteristics to others that one is green (Noppers, Keizer, Bolderdijk, \& Steg, 2014). However, when green products are privately consumed, these traditional other-signaling perspectives appear to have insufficient power to explain the consumer value stemming from this form of green consumption, given the absence of an external audience. Yet companies are increasingly launching green products in the category of privately consumed consumer goods, such as green

\footnotetext{
${ }^{1}$ A green product can be defined as a product that has been produced, delivered, and consumed with concerns about the negative externalities that such activities can have with regards to the environment, animals, and society.
} 
cleaning products, toiletries, or cooking ingredients. For instance, Walmart launched a private label green household brand to attract main- stream consumers in late 2013. Seventh Generation, a brand traditionally offering green cleaning products, has enjoyed double-digit growths in turnover over a period of ten years, resulting in over US \$200 million in 2015. Understanding why consumers value green products that are privately consumed is hence theoretically and managerially meaningful.

In the current research we draw from the concept of self-signals (e.g., Bénabou \& Tirole, 2004; Bodner \& Prelec, 2003; Prelec \& Bodner, 2003) and self-perception theory (Bem, 1972) to propose a model that can explain when and how self-signals impact consumer value of privately consumed green products. Self-signaling perspectives contend that consumers signal information to their own self through choices to satisfy epistemic needs regarding their self-views rather than to signal aspects of their selfs to others (Berger \& Heath, 2007; Brewer, 1991; Goldstein, Cialdini, \& Griskevicius, 2008; Holman, 1981; Wernerfelt, 1990). The notion of self-signaling is particularly well-suited to study value gained by consumers from green consumption because the nature of the trade-off involved in it implies opposing qualities about the consumer. Choosing a green product over a standard product incurs immediate costs in the form of lower quality or greater price but generates only indirect consumption benefits through improved ethics, such as environmental friendliness, reduced animal cruelty, or fewer chemicals and pesticides (Griskevicius et al., 2010; Lin \& Chang, 2012; Newman, Gorlin, \& Dhar, 2014). As such, choosing a green product over a standard product might be associated with self-sacrifice for the greater good, which signals positive traits to a consumer's self, such as pro-sociality and responsibility, whereas choosing a standard product over a green product might signal negative traits, such as selfishness or being cheap (Didonato \& Jakubiak, 2016; Lin \& Chang, 2012; 
Verplanken \& Holland, 2002). Self-signals, in turn, can extend the total consumption value of a product through the additional ego-utility consumers gain from self-related information, which leads to an incremental increase in the product's overall consumption value as reflected in higher consumer choice satisfaction or willingness to pay by consumers (e.g., Dhar \& Wertenbroch, 2012).

Yet our main proposition based on our model is that the insights consumers may get about their own underlying dispositions by choosing or abstaining from a green choice option may be valued differently by different consumers depending on their epistemic needs. Indeed, previous personality research found that some individuals will have clearer and more stable selfviews than others, a concept formally coined as self-concept clarity (SCC; Campbell et al., 1996), making it likely that those who have a more poorly defined notion of who and what they really are will systematically derive higher value from a positive self-signal from a choice than those who have a clearly defined self-concept. It thus stands to argue that consumers with lower self- concept clarity should value self-inferences more because they have higher epistemic needs with respect to their self-views than consumers with higher levels of self-concept clarity. We hence suggest that the incremental consumer value derived from a comparative choice of a green over a standard product depends not only on the self-signals associated with the choice but also on the consumer's level of self-concept clarity. We argue that the underlying mechanism is that the lower the clarity of a consumer's self-concept, the more value this consumer will derive from a choice generating self-information that is perceived to be in alignment with this consumer's own self-concept. By contrast, consumers with relatively high self-concept clarity have a strong and stable sense of who they really are and therefore will gain less incremental value from the perception that cues from self-signals are self-aligned. Based on this notion, self-signaling effects 
should similarly be provocable for consumers with high self-concept clarity when a choice is framed in a way that leads them to epistemically unfreeze their internal trait knowledge.

For the purpose of the present investigation, we conducted a series of studies, both in the lab and in the field. Drawing on self- reported self-concept clarity in Studies 1a, 1b, 3, and 4, and manipulated self-concept clarity in Studies 2 and 5, we find support for our proposed model across different types of green and standard products using different dependent variables. The present research seeks to theoretically extend existing self-signaling perspectives in marketing by examining the process through which self-signals result in consumer value for privately consumed green products (Dhar \& Wertenbroch, 2012; Savary, Goldsmith, \& Dhar, 2015). We extend the concept of self-signaling (e.g., Dhar \& Wertenbroch, 2012; Savary et al., 2015) to the domain of green consumption by proposing a self-signaling model that articulates a mechanism that can underpin the consequences of comparative choices of green versus standard products to ultimately explain the value added through self-signals. Importantly, the audience for such a selfsignal is internal, i.e., the consumer's self, as opposed to external, i.e., the selfs of other consumers - which is a more traditional perspective in marketing research (e.g., Goldstein et al., 2008; Griskevicius et al., 2010; Guthman, 2002; Janssen \& Jager, 2002; Pedersen, 2000; Van Vugt, 2009; Welsch \& Kühling, 2009). This relatively novel perspective enables us to address an important limitation of other-signaling perspectives - that is, to develop an understanding of how consumers value combinations of conventional versus green products based on the idea that the act of choosing one over the other signals information about consumers' own traits to themselves.

Furthermore, we conceptualize and empirically test an integrative self-signaling framework that explicates the central role of the self-concept in the appraisal of a self-signal by considering a broader net of concepts pertaining to the self, such as self-concept clarity and 
perceived self-concept alignment. Rather than providing only insights into the when of selfsignaling, this integrative approach allows us to unpack how self-signaling might function as a process. Such an understanding is important because it provides a more refined and nuanced perspective on self-signaling, leading us to appreciate that structural aspects of the self can act as an important boundary condition to the phenomenon of self-signaling.

Finally, this study offers implications and actionable insights predominantly for the marketing of privately consumed green products, such as toiletries, food ingredients, or household cleaners. These products can offer unique morally-related symbolic benefits to the consumer, which can sometimes be significant enough to thwart imagined or actual qualityrelated disadvantages of green products relative to their conventional counterparts. In order for companies to benefit from increased willingness to pay for these products, our findings suggest that these signaling benefits should be made salient at the moment of choice, through, for example, traditional marketing-mix elements including information provided in promotions, and on packaging. Marketers can explicitly promote a green product by framing a choice as an opportunity to learn or discover new, positive aspects about the own self. Such a framing may result in increased levels of willingness to pay even for consumers who are otherwise less susceptible to self-signals, i.e., consumers with relatively high levels of self-concept clarity. Next, we review important constructs that are phenomenologically linked to self-signaling and then develop hypotheses explicating our integrative framework.

2. Theoretical development and hypotheses

\subsection{Self-signaling}

The origins of the concept of self-signaling emerged mainly from the disciplines of psychology 
and economics. Many attribute its theoretical heritage to an often-cited experiment by Quattrone and Tversky (1984), identifying a cognitive inconsistency for pain tolerance. When subjects were led to believe that tolerance for a certain kind of pain (submerging one's hand in extremely cold water) was diagnostic of either a good or a risky heart condition, participants reacted by respectively extending or shortening the amount of time they withstood that pain of the cold water (Quattrone \& Tversky, 1984). Since the publication of this seminal study, research on the general phenomenon of self-signaling has gained momentum across several different fields (Baca-Motes, Brown, Gneezy, Keenan, \& Nelson, 2013; Bénabou \& Tirole, 2004, 2006; Bennett \& Chakravarti, 2008; Bodner \& Prelec, 1997; Dubé, Luo, \& Fang, 2017; McManus \& Rao, 2015; Mijović-Prelec \& Prelec, 2010; Monterosso \& Luo, 2010; Prelec \& Bodner, 2003; Savary et al., 2015; Sedikides, Gregg, Cisek, \& Hart, 2007; Verplanken \& Holland, 2002; Dhar \& Wertenbroch, 2012).

Self-signaling theory posits that people implicitly know their dispositions but have no conscious access to them - only through observing and interpreting their actual behavior can people discover or confirm what kind of person they really are (Bem, 1972; Prelec \& Bodner, 2003). A self-signal refers to the evidence that is derived from behaviors, e.g., from choices that an individual possesses certain desirable or undesirable traits, even when the behavior or choice has no, or very little, impact on the actual under- lying characteristic itself (Bénabou \& Tirole, 2004, 2006; Bodner \& Prelec, 2003; Mijović-Prelec \& Prelec, 2010; Prelec \& Bodner, 2003; Quattrone \& Tversky, 1984) - for example, choosing to buy a pair of Nike sneakers as evidence to the individual of his or her level of fitness. Similarly, when a consumer buys a green product, the consumer can interpret this choice as evidence of his or her environmental conscientiousness, while this purchase will, at the level of a single action, only have a slightly positive impact on the 
environment. Importantly, self-signaling benefits can materialize through the act of choice (Darke \& Chung, 2005). By choosing one option over others, a consumer reveals something about his or her underlying dispositions to his or herself (Prelec \& Bodner, 2003).

\subsubsection{Self-signaling and consumer value}

A self-signaling angle therefore implies that consumers not only gain functional value or utility from choices but also derive epistemic value from discovering or confirming aspects of who they really are. Thus the total value gained from choice includes an actual or anticipated functional value as well as the value that is derived from a self-signal (Bodner \& Prelec, 2003; Dhar \& Wertenbroch, 2012; Prelec \& Bodner, 2003). Per this view, positive self-signals from choices extend the overall consumption value of a product, defined as a consumer's global assessment of what is obtained in terms of the benefits of a product relative to what is given up in terms of the monetary and non-monetary costs (Bolton \& Drew, 1991; Zeithaml, 1988). Importantly, the notion of consumer value incorporates the global consumption experience of a consumer, which starts with and thus involves the transaction of the product (Thaler, 1985). Consumer value is typically assessed by a consumer's reservation price, i.e., the price beyond which a consumer would no longer be willing to buy a given product (e.g., Amir, Ariely, \& Carmon, 2008) but has also been inferred from consumer satisfaction in previous work (Dhar \& Wertenbroch, 2012). An added-on consumption value should then be reflected in higher consumer appraisal of value or higher willingness to pay by consumers (e.g., Dhar \& Wertenbroch, 2012).

\subsubsection{Self-signaling and self-concept clarity}

The pleasure or pain a consumer feels from acquiring news about his or her own self, however, might systematically vary as a function of a consumer's self-concept clarity. That is, how 
"clearly and confidently defined, internally consistent, and temporally stable" the self-concept is (Campbell et al., 1996, p. 141). The notion of self-concept clarity refers to the structural aspect of the self-concept (e.g., knowing clearly which attributes one possesses), which is viewed to be conceptually separated from its contents (e.g., perceived personal attributes) in social psychology (De Dreu \& Van Knippenberg, 2005; Demarree \& Morrison, 2012; Van Dijk et al., 2014; Wu, 2009). Indeed, research has found that the extent to which one knows the contents of his or her self-concept can chronically differ across individuals (Campbell et al., 1996; Luchies, Finkel, McNulty, \& Kumashiro, 2010; Mittal, 2015). Previous work on self-concept clarity found that individuals who have a less clearly defined self-concept tend to be low on internal trait awareness (Campbell et al., 1996). Thus, it appears likely that consumers with low self-concept clarity have higher epistemic needs regarding their selfs and would be relatively more impressed by obtaining favorable self-inferential news about their own internal traits from a self-signal associated with a choice than consumers with high self-concept clarity.

\subsubsection{Self-signaling and perceived self-concept alignment}

Our conceptualization of perceived self-concept alignment draws from self-consistency theories (e.g., Aronson, 1969; Festinger, 1957; Higgins, 1987; Thibodeau \& Aronson, 1992). We suggest that the intrinsic importance a self-signal has for the consumers plays an important role in the self-signaling process germane to green products. That is, the extent to which a positive selfsignal is perceived to be aligned with an individual's sense of who he or she really is is linked to the value a self-signal has for the individual.

Self-concept alignment will be the result of an appraisal that a self-signal verifies, confirms, or authenticates the self (Sedikides \& Strube, 1997). When an individual appraises a self-signal to be a true representation of his or her self-view, this individual is expected to 
perceive self-concept alignment. Believing to come to a deeper realization of what is most emblematic of one's true nature is what helps individuals to imbue life with a sense of authentic purpose (Schlegel, Hicks, Arndt, \& King, 2009) and to per- ceive a sense of control and predictability over a chaotic world (Alloy, Abramson, \& Viscusi, 1981; Golin, Terrell, \& Johnson, 1977; Golin, Terrell, Weitz, \& Drost, 1979; Swann, Stein-Seroussi, \& Giesler, 1992). Importantly, this appraisal can be the outcome of a rather naïve interpretation of the self-signal at face value, independent of previously existing preferences for green or conventional products. Indeed, the assumption that people only remember choices, but not the motivational states that led them to the choices, has been suggested by previous research (Ariely, Loewenstein, \& Prelec, 2000; Bénabou \& Tirole, 2000; Prelec \& Bodner, 2003). Thus, in line with this thinking, it should be the perception that a self-signal is a true representation of his or her self-view that transmits the effect of the signal on consumer value.

\subsection{Hypotheses}

\subsubsection{Model overview}

In a next step, we integrate self-concept clarity and perceived self-concept alignment to fully hypothesize a self-signaling process model that may underlie choices of a green over a standard product of which Fig. 1 provides an overview.

\section{------- Insert Figure 1 about here ---------}

\subsubsection{Hypotheses}

Our model rests on the key assumption originating from self-perception theory and self-signaling theories, that the true con- tents of one's self-concept are implicitly known but potentially 
unconscious (Bem, 1972; Prelec \& Bodner, 2003). They can, however, be materialized by choices that have the potential to uncover or confirm a consumer's underlying dispositions (Prelec \& Bodner, 2003). Consistent with this idea is a finding from previous social psychological research, which shows that verbal expression of attitudes leads individuals to believe in those attitudes more strongly (Higgins \& Rholes, 1978).

We predict that a choice of a green over a conventional product will be associated with a positive self-signal revealing an underlying disposition that one is prosocial and responsible rather than that one possesses negative traits, such as carelessness or selfishness (Didonato \& Jakubiak, 2016; Lin \& Chang, 2012; Verplanken \& Holland, 2002). Since such positive selfsignals indicate that the self is morally good, comparative choices of a green over a conventional product will likely lead to a stronger sense of self- concept alignment than will a choice of a conventional over a green product. It is, then, this appraisal of the good news from the self-signal as reflecting the self that provides the additional consumer value. This appraisal process, however, should be contingent on a consumer's level of self-concept clarity. It seems likely that consumers with higher levels of self-concept clarity will differ in their response to perceived self-concept alignment relative to those with lower levels of self-concept clarity. Since consumers with low self-concept clarity do not see the contents of their self-concept as clearly (Campbell et al., 1996), they should generally react more favorably to the positive selfinformation contained in a self-signal. They will likely be more impressed by the good news about themselves as they are lower on internal trait knowledge than consumers with high selfconcept clarity (Campbell et al., 1996). Hence they should derive higher value from the inferences about themselves and their underlying characteristics from a self-signal, which should lead to a stronger incremental effect on consumer value derived from choice. By contrast, 
consumers with relatively high levels of self-concept clarity hold a clear and confident view of their self-concept, and, as a consequence, self-information that updates or verifies the self is less relevant for them. Thus they should derive less incremental value from perceived self-concept alignment. It follows then that consumers with low self-concept clarity will derive higher incremental value from a signal that is perceived to be aligned with their self-concept than consumers with high self-concept clarity. More formally we therefore propose:

H1. The overall effect of self-signals induced from comparative choices of a green versus a conventional product on consumer value will be moderated by self-concept clarity, such that a choice of a green over a standard product leads to higher incremental consumption value for consumers with low than for consumers with high self-concept clarity.

This moderation of the overall effect might occur because:

H2. For consumers with low self-concept clarity, the effect from a self-signal induced by choice on consumer value will be transmitted by the extent to which it is perceived to be aligned with their self-concept, such that consumers with low self-concept clarity will derive higher incremental value from a self-signal that is perceived to be aligned with their self-concept than consumers with high self-concept clarity.

\section{Overview of studies}

We next present six studies to test our hypotheses. Studies $1 \mathrm{a}, 1 \mathrm{~b}$, and 2 were designed to test our main hypothesis H1. In Study 1a, we conducted an initial test of the joint effect of a self-signal induced from comparative choices of green versus standard products and self-concept clarity on consumer value by manipulating self-signal strength from choice and measuring self-reported 
self-concept clarity. We also contrasted our self-signal account against an other-signal account to rule out whether self-signaling has value beyond other-signaling in the context of private green consumption. The goal of Study $1 \mathrm{~b}$ was to re-test the joint effect of a self-signal and self-concept clarity in a field context using a different product category and dependent variable than that in Study 1a. With Study 2 we attempted to derive stronger causal inferences about the moderating role of self-concept clarity by manipulating self-concept clarity rather than employing selfreported self-concept clarity. The primary goal of Study 3 was to uncover by what means selfsignals and self-concept clarity jointly impact consumer value, which is to shed light on the underpinning psychological mechanism behind the proposed joint effect of self-signals and selfconcept clarity on consumer value. Study 3 was thus designed to provide a formal test of $\mathrm{H} 2$. Finally, the goal of Study 4 and Study 5 was to further test the validity of our self-signaling account. If our account had some validity, we would find that the value added for green compared to standard products would ironically be reduced through price discounts - particularly so for consumers with relatively low levels of self-concept clarity - and that self-signaling could be "switched on" for consumers with relatively high levels of self-concept clarity if the choice would be framed as an opportunity to learn new positive aspects about one's self.

4. Study 1a: The joint effect of self-concept clarity and self-signals on consumer value The purpose of Study 1a is to provide an initial test of H1, in which we proposed that selfconcept clarity negatively moderates the relationship between positive self-signals induced from choice and the level of consumer value.

\subsection{Participants}

We recruited participants from the United States through Amazon Mechanical Turk (Mturk) in 
exchange for a nominal payment. For all the main experimental studies reported in this paper, we determined sample sizes based on an a priori power analysis using an alpha level of 0.05 , power of 0.8 , and small to medium effect sizes for the effect of green over standard assigned choice, which we determined based on pre-tests (Cohen, 1988). Given that we were interested in testing moderation effects of self-concept clarity, we increased sample size accordingly to be conservative (Goodman \& Lim, 2018).

MTurk provides data as reliable as that collected from more traditional sampling methods (Buhrmester, Kwang, \& Gosling, 2011) but is critiqued for mindless responding (Chandler, Mueller, \& Paolacci, 2014). Thus we analyzed only responses of participants who passed an attention check (correctly reporting the assigned choice). Also, because willingness to pay was assessed in an open-ended manner, we followed past research that has removed extreme values for such measures (Omtzigt \& Hendriks, 2004; Simonson \& Drolet, 2004), and omitted responses from forty-four participants. We further excluded data from thirty- eight respondents who indicated that they did not see the pictures in the vignettes. We obtained usable responses from two- thousand one-hundred and six participants (males $=48.4 \%$, mean age $=38.67$ years). Mean income was between $\$ 40,000$ and $\$ 59,000$ USD per year.

\subsection{Study design}

We employed a 2 (assigned choice of green vs. standard brand) $\times 2$ (high vs. low self-signals [+ 1 other-signal]) between- participants design with self-concept clarity measured as a continuous variable. The other-signaling condition merely served as a control condition, against which we aimed to empirically contrast the high self-signal condition, in which a self-signal would naturally occur. Participants were randomly assigned to one of the conditions. The experimental stimuli appear in Appendix A. 
Respondents in all conditions were first presented with an image of two bottles of laundry detergent distinguished by the color of the lids (green or silver) and the labels. We used bottles of a real Canadian brand of laundry detergent that is not available in the United States and thus would not be known to participants but provides external validity. The choice scenarios indicated to the participants that they chose either the standard (Original) or the green (Free/Nature) product. Standard versus green products imply a trade-off between perceived product quality and environmental benefits for consumers, such that consumers believe they need to decide between something of higher quality that is environmentally harmful and something of lesser quality that is environmentally beneficial (Griskevicius et al., 2010; Haws, Winterich, \& Naylor, 2013; Lin \& Chang, 2012; Newman et al., 2014). While product quality is functionally beneficial for the individual, sustainability is beneficial to the environment. Thus choosing a green product over a standard product will signal to the individual that he or she cares for the environment (BacaMotes et al., 2013; Didonato \& Jakubiak, 2016; Verplanken \& Holland, 2002) where environmentalism is almost universally recognized as a positive trait (Haws et al., 2013; Steg \& De Groot, 2012). By contrast, choosing a standard product over a green product will signal to the individual that he or she is selfish by putting functional benefits above environmental ethics. Laundry detergent was chosen as the product category is in connection to the environmental debate surrounding water pollution, implying a trade- off between quality and sustainability (Goel \& Kaur, 2012; Meays \& Nordin, 2013). ${ }^{2}$

\footnotetext{
${ }^{2}$ We conducted a separate pretest to examine the assertion that consumers would ascribe lower product quality to the green compared with the standard brand of laundry detergent. After exposing three-hundred seventeen Mturkers to the same picture of laundry detergents we used in the vignette for this study, we asked them to rate the cleaning effectiveness of the standard versus the green brand of laundry detergent on a sevenpoint semantic differential scale, from "the standard brand is more effective in removing stains" ( -3$)$, to "the green brand is more effective in removing stains" (3), as the end-points of the scale. We find the resulting score to be significantly lower than the neutral point of the scale (0), such that the standard brand is rated significantly higher on quality than the green brand $\left(\mathrm{M}_{\mathrm{qlty}}=-0.32 ; \Delta\right.$ from $\left.0 ; \mathrm{t}(316)=-4.18, \mathrm{p}<.001\right)$.
} 
We manipulated the strength of the occurring self-signal associated with the assigned choice of laundry detergents by inducing people to make contextual attributions rather than selfattributions in the low self-signal condition and by inducing an other- signal as opposed to a selfsignal in the other-signal condition. To this end, we added a sentence in the text under the image in the other and the low self-signal condition. In the low self-signal condition, respondents read an instructional statement explaining that they made the choice only because they were allergic to an ingredient of the other available brand, diluting the self-diagnostic value of the choice (see Dhar \& Wertenbroch, 2012 for a similar manipulation) and in the other-signal condition that the choice is being made due to other shoppers observing the participant.

\subsection{Procedure}

Participants first completed a self-concept clarity measure, a four-item scale adopted from Campbell et al. (1996) that included items such as "my beliefs about myself rarely change" and "I feel I am the person I appear to be" on a 7-point Likert scale $(1=$ strongly disagree, $7=$ strongly agree). Items were averaged to form a self-concept clarity index $(\alpha=0.84)$. After completing some filler tasks, which included a logic puzzle and one color-ordering task, respondents were then presented with the image of the two bottles of laundry detergent and a text under the image that included the manipulations. The attention check was in- cluded after the vignette. The dependent variable in all conditions is willingness to pay (WTP). The WTP measure asked respondents to consider what is the maximum they'd be willing to pay for the laundry detergent brand that the vignette indicated to them they had chosen, prompting an amount in USD. Participants completed self-attribution-based measures of self-signals. Based on the assigned choice of laundry detergent indicated in the vignette, participants were asked to state their agreement with the following statements: "If you would make this choice of laundry 
detergent, how would you feel? Like I were a good person, Like I were compassionate, Like I were sympathetic, Like I were cheap (reverse coded), Like I were selfish (reverse coded)" on a 7-point Likert scale $(1=$ strongly disagree, $7=$ strongly agree $)$. We formed an index of these items $(\alpha=0.73)$. Respondents were asked to complete further questions, including information about their demographics and a check of whether the pictures in the vignette have been properly displayed.

\subsection{Results}

\subsubsection{Manipulation check}

We performed a regression analysis, with assigned choice ( $\operatorname{standard}=-1$, green $=1)$, signal strength (high $=-1$, low $=1)$, their interaction as independent variables, and the self-attributional measure as the dependent variable. Results show that choices of the green over the standard product were associated with a significantly stronger positive self-signal than choices of the standard over the green product $(\mathrm{b}=0.304, \mathrm{t}(1412)=10.90, \mathrm{p}<.001 ; \mathrm{M}(\operatorname{grn} \mid \mathrm{std})=4.79$ vs. 4.18), and a marginal significant main effect of signal strength on the occurrence of positive selfsignals $(\mathrm{b}=0.046, \mathrm{t}(1412)=1.66, \mathrm{p}=.097 ; \mathrm{M}($ low $\mid$ high $)=4.53$ vs. 4.44 $)$. Importantly, attesting to the contextual attributions induced in the low self-signal condition, a significant interaction effect between assigned choice and signal strength $(b=-0.119, t(1412)=-4.27, p<.001)$ occurred, such that the assigned choice of a green over a standard product is associated with a stronger positive self-signal in the high self-signal condition (high self-signal: $\mathrm{M}(\mathrm{grn} \mid \mathrm{std})=4.86$ vs. 4.02) than in the low self-signal condition (low self-signal: $M(\operatorname{grn} \mid \operatorname{std})=4.72$ vs. 4.35$)$. Overall, results of this regression analysis indicate that our manipulations were effective and in line with our theorizing. 


\subsubsection{Self vs. other-signals}

We again regressed the self-attributional measure on assigned choice ( $\operatorname{standard}=-1$, green $=1$ ), signaling condition ( self $=-1$, other $=1$ ), and their interaction. Results show again a significant main effect of assigned choice, such that an assigned choice of the green product was associated with a significantly stronger positive self-signal than a choice of the standard product $(b=0.431$, $\mathrm{t}(1391)=14.07, \mathrm{p}<.001 ; \mathrm{M}(\mathrm{grn} \mid \mathrm{std})=4.65$ vs. 3.79). Furthermore, there is a significant negative main effect of signaling condition on the occurrence of positive self-signals $(b=$ $-0.219, \mathrm{t}(1391)=-7.14, \mathrm{p}<.001)$, such that assigned choices in the self-signal condition are related to stronger positive self-signals than in the other-signal condition $(\mathrm{M}($ self $\mid$ other $)=4.44$ vs. 4.00). The interaction effect between assigned choice and signaling condition is nonsignificant $(\mathrm{b}=0.008, \mathrm{t}(1391)=0.261, \mathrm{p}=.794$; self: $\mathrm{M}(\mathrm{grn} \mid \mathrm{std})=4.86$ vs. 4.02 ; other: $\mathrm{M}(\operatorname{grn} \mid \mathrm{std})=4.44$ vs. 3.56).

\subsubsection{Hypothesis testing}

We regressed willingness to pay on assigned choice ( standard $=-1$, green $=1$ ), signal strength $($ high $=-1$, low $=1)$, mean-centered self-concept clarity and all interactions among them. While the main effect of assigned choice is significant $(b=0.473, t(1408)=4.45, p<.001)$, the main effects of self-concept clarity and signal strength are not (self-concept clarity: $b=-0.093$, $\mathrm{t}(1408)=-1.077, \mathrm{p}=.282$; signal strength: $\mathrm{b}=-0.098, \mathrm{t}(1408)=-0.921, \mathrm{p}=.357)$. Importantly, the three- way interaction between assigned choice, signal strength, and self-concept clarity is significant and in line with our theorizing $(b=0.173, t(1408)=2.01, p=.045)$. In addition, there is a significant two-way interaction between assigned choice and signal strength $(b=-0.251$, $\mathrm{t}(1408)=-2.36, \mathrm{p}=.018)$ but no other interaction effect is significant $($ at $\mathrm{p}<.05)$. 
Decomposing the three-way interaction, in the high self-signal condition, there is a significant simple effect of assigned choice of the green over the standard brand $(0=$ standard and $1=$ green) at the mean level of self-concept clarity $(b=1.44, \mathrm{t}(697)=4.39, \mathrm{p}<.001)$, and a significant negative choice $\times$ self-concept clarity interaction $(b=-0.684, \mathrm{t}(697)=-2.59, \mathrm{p}=$ $.010)$, such that consumers with relatively low levels of self-concept clarity have a significantly higher willingness to pay for the green versus the standard brand while this difference becomes non-significant for consumers with relatively high levels of self-concept clarity. Indeed, consumers stop being willing to pay significantly more for a choice of the green over the standard brand for levels of self- concept clarity that are larger than 0.93 units above the mean of self-concept clarity (at $\mathrm{p}<.05$; Fig. 2; see also Spiller, Fitzsimons, Lynch Jr., \& McClelland, 2013).

Consistent with our predictions, self-signaling effects are significantly reduced in the low self-signal condition, i.e., when it was indicated to participants that they made the choice only because they were allergic to an ingredient of the other available brand. Attesting to the then lower strength of the self-signal, there is only a close to marginal significant simple effect of assigned choice of the green over the standard brand $(b=0.444, t(711)=1.64, p=.103)$, and no significant interaction effect with self-concept clarity $(b=0.010, t(711)=0.044, p=.965)$.

In sum, these results suggest that positive self-signals from a choice of a green over a standard product are associated with incrementally more consumption value - but statistically significant only for consumers with relatively low to above medium levels of self-concept clarity, supporting H1. 


\subsubsection{Other-signaling account}

We have proposed that the key property that distinguishes self-signaling from other-signaling is that the underlying psycho- logical needs differ, such that other-signaling is directed at instilling a desired image in other consumers, whereas self-signaling is based on an epistemic need regarding the consumer's own self. Although with green products that are typically privately purchased and consumed, self-signals rather than other-signals should generally be most pertinent; we aim to further illustrate the value of our self-signaling account by contrasting it with other-signaling. Based on our previous theorizing, we expect that when positive signals from choices are predominantly directed towards other consumers, the self-diagnosticity of choices for one- self will be dampened. In order to examine this issue, we had introduced an other-signaling condition as a second between- participants control group, which we empirically compare with the high self-signal condition.

We regressed willingness to pay on assigned choice ( standard $=-1$, green $=1$ ), signaling condition (self-signaling $=-1$, other signaling $=1$ ), mean-centered self-concept clarity, and all interactions among them. The main effect of assigned choice is significant $(b=0.455, t(1387)=$ $4.00, \mathrm{p}<.001)$. The main effects of self-concept clarity and signaling condition are not significant (self-concept clarity: $\mathrm{b}=0.006, \mathrm{t}(1387)=0.063, \mathrm{p}=.950$; signaling condition: $\mathrm{b}=$ $-0.004, \mathrm{t}(1387)=-0.034, \mathrm{p}=.973)$, neither is the two-way interaction between signaling

condition and self-concept clarity $(b=0.092, t(1387)=1.03, p=.305)$. We find that the two-way interaction between assigned choice and signaling condition is significant, such that the positive main effect of assigned choice of the green product is significantly reduced in the other-signal condition $(\mathrm{b}=-0.269, \mathrm{t}(1387)=-2.36, \mathrm{p}=.018)$, and a significant two-way interaction between assigned choice and self-concept clarity $(b=-0.194, t(1387)=-2.17, p=.030)$. The three-way 
interaction between assigned choice, signaling condition, and self-concept clarity is marginally significant $(b=0.148, t(1387)=1.65, p=.098)$, such that the dampening effect of othersignaling on the link between assigned choice of a green over a standard product on willingness to pay is weaker for consumers with relatively high levels of self-concept clarity than for consumers with relatively low levels of self-concept clarity. Turning to the effects in the othersignaling condition more specifically, we find that there is no significant simple effect of choice of the green over the standard brand on willingness to pay $(b=0.374, t(690)=1.15, p=.252)$ at the mean of self-concept clarity, nor a significant interaction with self-concept clarity $(b=$ $-0.093, t(690)=-0.364, p=.715$; see Fig. 3). Overall, this pattern of results indicates that othersignals can crowd out self-signals from choices - specifically so for consumers with relatively low levels of self-concept clarity, as it is these consumers who derive the highest incremental value from such choices when self-signals are intact. These findings suggest that there is indeed some value in our self-signaling account.

\section{Insert Figure 3 about here}

5. Study 1b: The joint effect of self-concept clarity and self-signals on choice satisfaction Evidence from a field study

The results from Study 1a provide initial evidence for our prediction that the relationship between self-signals arising from a comparative choice of a green product and consumer value is contingent on a consumer's self-concept clarity. In a next step, we aimed to test whether the main findings from Study 1a would also hold for real consumer choices in the field. We focused on a choice set that conceptually mimics the vignettes we had used in Study 1a. We measured choice satisfaction instead of willingness to pay as the dependent variable. This is to acknowledge previous work, which found that monetary measures of consumer value can sometimes fall short 
to sufficiently reflect how consumers experience the acquisition or consumption of a product (Amir et al., 2008). As the interpretation of a self-signal from choice may well be one such factor, and given that we examined real transactions, we measured choice satisfaction instead of willingness to pay in Study 1b. Choice satisfaction taps a consumers' overall cognitive and affective states arising from a particular transaction, episode, or encounter (Oliver, 1993).

\subsection{Participants}

Approximately five hundred shoppers were approached to participate in our study when they made a selection from the milk display of a mid-size urban supermarket in a large European city. One hundred and sixty-four customers agreed to participate $($ males $=46.3 \%$, mean age $=32.55)$. Mean income was between \$26,325 and \$51,335 USD per year.

\subsection{Study design and procedure}

Participants were approached at the supermarket if they selected a container of either organic or standard milk from the dairy display and were asked to answer a brief survey based on their selection. A member of our research team, who was unobtrusively posing further down the aisle as a shopper, distributed the survey. They approached respondents to participate in the study when they observed a shopper making an unprompted selection of either standard or organic milk in the dairy aisle. We used milk versus organic milk as the focal products in this field study. Choosing organic milk over standard milk should generate a self-signal that the consumer is environmentally conscious and willing to sacrifice financially to support this belief, whereas choosing standard might imply that the consumer prioritizes price concerns over ethics.

After noting which milk they chose out of a variety of choices on the shelves, participants completed a survey on a tablet. We measured the dependent variable choice satisfaction using 5 
items adapted from Oliver (1997). We used a 7-point Likert scale for all items $(1=$ strongly disagree, 7 = strongly agree). Respondents were asked to indicate agreement to statements such as "I am very satisfied with my decision to buy the milk" and "If I could do it over again, I would make the same decision." The items were averaged to form a satisfaction index $(\alpha=0.93)$. Respondents also completed the same self-concept clarity measure as in Study la $(\alpha=0.86)$. Finally, respondents were asked to complete questions about their demographic information, including age, gender, ethnicity, and income.

\subsection{Results}

We introduced a dummy variable to denote whether a respondent chose the standard (coded 0) or the organic brand of milk (coded 1), and then regressed choice satisfaction on choice (standard vs. green), mean-centered self-concept clarity, and their interaction. Results reveal a significant negative interaction effect between choice and self-concept clarity $(b=-0.415, \mathrm{t}(160)=-2.53, \mathrm{p}$ $=.013)$. The main effect of self-concept clarity on choice satisfaction is positive and significant $(b=0.375, t(160)=4.78, p<.001)$. The simple effect of choice of a green over a standard product on satisfaction is non-significant $(b=0.240, \mathrm{t}(160)=1.17, \mathrm{p}=.243)$. In order to enhance interpretation of the interaction, we plotted the interaction effect and determined the Johnson-Neyman point (Fig. 4). Consumers gain significantly more satisfaction from a choice of a green relative to a choice of a standard brand for any levels of self-concept clarity slightly below the mean of self-concept clarity $(-0.38$; at $\mathrm{p}<.05)$. These findings suggest that choosing a green product over a standard product leads to added consumption value primarily for the consumers with relatively low levels of self-concept clarity. 


\subsection{Discussion}

The results from Studies 1a and $1 \mathrm{~b}$ support the proposition that a choice of a green product over a standard product leads to added consumption value primarily for the consumers with relatively low levels of self-concept clarity. That is, with increasing levels of self-concept clarity, the difference in value consumers derive from a comparative choice of a green versus a comparative choice of a conventional product decreases incrementally. We find this contingency to hold for assigned choices (Study 1a) and for real consumer choices (Study 1b), and for multiple measures of consumer value (WTP, choice satisfaction).

Furthermore, the results also suggest that with increasing levels of self-concept clarity, the value consumers derive from a choice of a conventional over a green product increases incrementally. This finding might imply that just as little as consumers with high self-concept clarity value positive self-signals from a choice of a green over a standard product, so too will they derive little negative self-signaling value from a choice of a conventional over a green product compared with consumers with low self- concept clarity (Bodner \& Prelec, 2003).

Furthermore, the results suggest that self-signals rather than other-signals underlie our model because it does not hold when consumers make choices solely for signaling to others. Thus the desire to instill a social image in others can, in some cases, in fact, dilute self-signals. It is of note that there might be cases where self- and other-signals interact in functional ways because they are not incompatible with each other.

In these studies participants naturally inferred trade-offs of an image or from real products in the field. To provide a more unequivocal test of our hypothesis, in a next step we portrayed the trade-offs explicitly using a written vignette.

\section{Study 2}


In Study 2, we aim to draw stronger causal inferences about the moderating effect of self-concept clarity on the link between self-signals from choices of green over standard products and consumer value. To this end, we manipulated self-concept clarity as opposed to relying on selfreported levels of self-concept clarity as in Studies 1a and 1b. Furthermore, we used written vignettes that described the trade-off between the green and the standard product as experimental stimuli.

\subsection{Participants}

We recruited participants from the United States through Amazon Mechanical Turk (Mturk) in exchange for a nominal payment. We analyzed only responses of participants who passed an attention check (correctly reporting the assigned choice). We omitted responses from eighteen participants who reported extreme willingness to pay values and excluded responses from fortyseven participants who were not diligent in completing the self-concept clarity manipulation (e.g., copying and pasting our instruction texts). We obtained usable responses from sevenhundred and eighty respondents (mean age $=38.19$, males $=46.5 \%$ ). Mean income of respondents was between $\$ 40,000$ and $\$ 59,000$ USD per year.

\subsection{Study design and procedure}

We employed a 2 (assigned choice of green vs. standard brand) $\times 2$ (high vs. low self-concept clarity) between-participants design. We randomly allocated participants to one of the conditions. In order to experimentally manipulate self-concept clarity, we asked participants to complete a task developed by Rozenkrants, Wheeler, and Shiv (2017) that was designed to increase or decrease participants' self-concept clarity. Participants were prompted to consider a time when they felt respectively clear or conflicted about their sense of self: 
There are times when you have [don't have] a clear and consistent sense of who you really are, when you feel like you [don't] truly know what you are like. You have consistent [conflicting] views about yourself that do not change over time [shift from day to day]. For example, you may have felt clear [conflicted] and sure [unsure] about particular traits or aspects of yourself or been in a situation that displayed that you had a clear [conflicting] sense of yourself.

Please take a few minutes to recall and immerse yourself in a time when you felt that you had [didn't have] a clear and consistent view of who you really were.

Participants were then asked to describe this reflection in detail. A separate pre-test of this manipulation with ninety-nine Mturkers showed that it effectively manipulated self-concept clarity; participants in the high self-concept clarity condition reported significantly higher levels of self-concept clarity (Mhigh_SCC $=5.68$ ), as assessed with the same self-concept clarity measure as in Studies 1a and 1b, than those in the low self-concept clarity condition (Mlow_SCC $=4.64 ; \mathrm{t}(97)=3.89, \mathrm{p}<.01)$. Respondents were then presented with a written vignette depicting two types of laundry detergent (see Appendix B). ${ }^{3}$ The laundry detergents were depicted as either green or standard based on the presence or absence of environmentally harmful, but effective, chemicals, implying a trade-off between quality and sustainability (Goel \& Kaur, 2012; Meays \& Nordin, 2013). The vignette indicated that the respondent had chosen either the standard or the green brand. The attention check was included after the vignette. Willingness to pay was again the dependent variable. Respondents were asked further questions, including some

\footnotetext{
3 A pretest with ninety Mturkers confirmed that the manipulation of self-signals with this vignette was successful. We regressed the selfattributional measure on assigned choice ( $\operatorname{standard}=-1$, green $=1$ ). Results show that choices of the green over the standard product were associated with a significantly stronger positive self-signal than choices of the standard over the green product $(b=0.602, t(88)=4.96, \mathrm{p}<.001$; $\mathrm{M}_{(\mathrm{grn} \mid \mathrm{std})}=5.58$ vs. 4.38$)$.
} 
about their demographics.

\subsection{Results and discussion}

\subsubsection{Hypothesis testing}

Our framework holds that participants with relatively low levels of self-concept clarity would derive higher consumer value from a choice of a green over a standard brand than participants with relatively high levels of self-concept clarity. For hypothesis-testing, we regressed willingness to pay on assigned choice $($ standard $=-1$, green $=1)$, manipulated self-concept clarity (low $=-1$, high $=1$ ), and their interaction. While the main effect of green over standard assigned choice is significant, there is no significant main effect of self-concept clarity on willingness to pay (assigned choice: $\mathrm{b}=0.675, \mathrm{t}(776)=3.35, \mathrm{p}=.001, \mathrm{M}(\mathrm{grn} \mid \mathrm{std})=9.22 \mathrm{vs}$. 7.87; self-concept clarity: $\mathrm{b}=-0.049, \mathrm{t}(776)=-0.243, \mathrm{p}=.808, \mathrm{M}($ low $\mid$ high $)=8.59$ vs. 8.49). Importantly, the interaction between choice and self-concept clarity is significant and in line with our hypothesis $(b=-0.451, \mathrm{t}(776)=-2.24, \mathrm{p}=.025)$.

Examining this interaction more closely, the effect of assigned choice (green $=1$, standard $=0$ ), on willingness to pay is positive and significant when participants had relatively low self-concept clarity $(b=2.25, \mathrm{t}(398)=3.81, \mathrm{p}<.001)$, such that those who were assigned to the choice of the green brand reported higher willingness to pay $(M=9.72)$ than those who were assigned to the choice of the standard brand $(M=7.47)$. By contrast, when self-concept clarity was relatively high, the effect of choice on willingness to pay is non-significant $(b=0.447$, $\mathrm{t}(378)=0.822, \mathrm{p}=.412)$. Those who were assigned to the choice of the green brand did not report significantly higher levels of willingness to pay $(\operatorname{Mgrn}=8.72)$ than those who were assigned to the choice of the standard brand $\left(\mathrm{M}_{\mathrm{Std}}=8.27\right.$; see Fig. 5). 
In summary, this pattern of results corroborates the key finding that consumers with relatively high levels of self-concept clarity derive less incremental value from a positive selfsignal than consumers with relatively low levels of self-concept clarity. The results of Study 2 extend the findings from Studies 1a and $1 \mathrm{~b}$ by relying on manipulated rather than on selfreported levels of self-concept clarity, which allows us to draw stronger causal inferences about the moderating role of self-concept clarity.

\section{Study 3: Underlying mechanism}

Although we empirically showed that consumer value derived from a self-signal is a function of consumers' level of self- concept clarity, a mechanism that may underlie this relationship has yet to be empirically explicated. The primary goal of Study 3 is hence to test H2. In hypothesis 2, we propose that the perception that a self-signal is aligned with the consumer's self is what imbues a self-signal with value for the customer, and that the value appraisal based on self-concept alignment varies with different levels of consumer self-concept clarity. We test our proposition in a high and low self-signal condition.

\subsection{Participants}

We recruited participants from the United States through Amazon Mechanical Turk (Mturk) in exchange for a nominal payment. We analyzed only responses of participants who passed an attention check (correctly reporting the assigned choice). We excluded data from ten respondents who indicated that the pictures in the vignettes were not displayed. We obtained usable responses from seven-hundred and seventy-two participants $($ male $=51.2 \%$, mean age $=38.50)$. Mean income was between $\$ 40,000$ and $\$ 59,000$ USD per year. 


\subsection{Study design and procedure}

We employed a 2 (assigned choice of green vs. standard brand) $\times 2$ (high vs. low self-signals) between-participants design with the self-concept clarity measure as a continuous variable. We used the same self-concept clarity scale $(\alpha=0.83)$, filler tasks, and manipulations as in Study 1a (the vignette depicting the image of the two laundry detergents, with the low self- signal condition, dampening the self-diagnostic value of the choice; see Appendix A). Respondents were presented with the image of the two bottles of laundry detergent and the text under the image, which included the manipulations. The attention check was included after the vignette. The dependent variable in all conditions is willingness to pay (WTP). In contrast to the open-end willingness to pay measures we had used in Study 1a and Study 2, we employed an interval scale from Rucker and Galinsky (2008) in Study 3 to reduce response variety that may exist due to undue reference prices respondents may have held (e.g., Simonsohn \& Loewenstein, 2006). We asked participants to state their willingness to pay for the respective brand of shampoo on a 12point scale, from $1=10 \%$ of the retail price of the item to $12=120 \%$ of the retail price. Respondents completed a 5 -item perceived self-concept alignment measure $(\alpha=0.95)$. We asked participants to indicate the extent to which they felt the choice matched with the characteristics of their true self on a 7-point semantic differential scale. Items were "When I see myself making this choice, it doesn't reflect my true self... it does reflect my true self," "When I see myself making this choice, it doesn't match my true self... it does match my true self," "Observing myself making this choice, it does not match who I really am as a person... does match who I really am as a person," "Observing myself making this choice, it does not match what I stand for... does match what I stand for," and "My feelings did not match the choice I made in the above scenario... did match the choice I made in the above scenario." Respondents completed 
some further scales, including demographic questions.

\subsection{Study 3 results}

\subsubsection{Hypothesis testing}

Across Studies 1a, 1b, and 2, we found converging evidence for a joint effect of self-signals from comparative choices and self- concept clarity on consumer value. In $\mathrm{H} 2$, we hypothesize a mediating chain. Specifically, we expect that the effect of self-signals from choices of green over standard products will be transmitted via perceived self-concept alignment on consumer value when consumers have relatively low levels of self-concept clarity because these consumers will gain significant incremental value from a self-signal confirming their self-concept. To formally test H2, we specified the model depicted by Fig. 6 (this model is equivalent to Model 15 of the PROCESS bootstrapping procedure; Hayes, 2013) and conducted a mediation analysis, relying on a bootstrapping analysis with 10,000 random draws. We estimated identical models for both the high and low self-signal conditions. We tested for significance of the indirect effects conditional on different values of the moderator self-concept clarity in each condition and compared the indirect effect for being significantly different across the low and high self-signal condition.

We find that the $95 \%$ bias-corrected confidence interval for the indirect effect of positive self-signals at the mean of self-concept clarity via self-concept alignment on willingness to pay excludes zero in the high self-signal condition (indirect effect: $b=0.383,95 \%$ CI: $0.121,0.696$ ) but includes zero in the low self-signal condition (indirect effect: $\mathrm{b}=0.013,95 \% \mathrm{CI}$ : -0.079 , 0.103). In line with our theoretical account, this pattern indicates that there is significant mediation in the high self-signal condition but not in the low self-signal condition. Furthermore, 
since the confidence intervals for the indirect effects in the high and low self-signal conditions are non-overlapping, the indirect effect in the high self-signal condition is significantly larger than in the low self- signal condition at $\mathrm{p}<.05$. As such, $\mathrm{H} 2$ is supported.

In order to further examine the significant indirect effect in the high self-concept clarity condition, we determined the values of self-concept clarity for which the conditional indirect effect of positive self-signals on customer willingness to pay through self- concept alignment is statistically significant (Hayes \& Matthes, 2009; Johnson \& Fay, 1950; Johnson \& Neyman, 1936; Spiller et al., 2013). As Fig. 6 illustrates, participants stop gaining significant incremental value from a self-signal associated with a choice of a green over a standard product at slightly above moderate levels of self-concept clarity (the Johnson-Neyman-point [1936] is at 0.66 units above the mean of self-concept clarity; at $\mathrm{p}<.05$ ) in the high self-signal condition. Overall, this pattern of results sup- ports $\mathrm{H} 2$.

\section{Insert Figure 6 about here}

\subsection{Discussion}

Results of Study 3 corroborate our self-signaling account by demonstrating that perceived selfconcept alignment underlies the joint effect of positive self-signals from choice and self-concept clarity on willingness to pay for consumers with relatively low levels of self-concept clarity. When those consumers obtain a positive self-signal from choice, they perceive that this signal is aligned with their self-concept, and this perception is associated with a positive, incremental increase in consumer value. It is as if they interpret the perceived alignment of a positive selfsignal as surprising news about themselves and derive instant ego- utility from having uncovered or confirmed an aspect about their self. Yet for consumers with relatively high values of selfconcept clarity, there is no significant indirect effect of positive self-signals via self-concept 
alignment on willingness to pay, such that when consumers with relatively high levels of selfconcept clarity obtain a positive self-signal from choice, they perceive that this signal is aligned with their self-concept, but they do not derive significant incremental consumption value from this perception. As such, these results demonstrate that self-concept clarity and perceived selfconcept alignment can explicate a mechanism underlying the link between self-signals triggered by comparative choices of green over standard products and consumer value from choice.

\section{Study 4: Price promotions and self-signaling}

Price discounts act as promotional tools for managers because they are thought to increase the transaction value of a choice (Thaler, 1985). They are not limited to conventional products; instead, they are increasingly applied to products with prosocial and green characteristics (e.g., Andrews, Luo, Fang, \& Aspara, 2014). Yet, assuming that our self-signaling account has some validity, it appears likely that regular price discounts may well lead consumers to make contextual attributions for their choices (i.e., attributing the choice to the discount rather than to their self), which may reduce positive self-signals from choices. Initial evidence for a crowdingout effect of price discounts can be found in Dubé et al.'s (2017) work - albeit without providing a test of self-signaling underlying their findings. Based on our self-signaling account, we suggest that price promotions may crowd out self-diagnostic benefits of a privately consumed green product for consumers with relatively low levels of self- concept clarity, such that these consumers would ironically gain very little surplus in consumer value through a price discount but that consumers with relatively high levels of self-concept clarity are less vulnerable to a crowding-out effect, which should lead them to derive more value from a price discount than consumers with relatively low self-concept clarity. Examining this issue is managerially relevant because price promotions are the most common form of sales promotions employed by 
marketers (e.g., Darke \& Chung, 2005).

\subsection{Participants}

We recruited participants from the United States through Amazon Mechanical Turk (Mturk) in exchange for a nominal payment. We obtained responses from one-thousand and seventeen participants $($ males $=45.5 \%$, mean age $=35.87$ years $)$; mean income was between $\$ 40,000$ and $\$ 59,000$ USD per year.

\subsection{Study design}

We employed a 2 (assigned choice: green vs. standard brand) $\times 2$ (price promotion: no price promotion vs. price promotion offered) between-participants design with self-concept clarity measured as a continuous variable. We used shampoo as the product category in Study 4. Shampoos are privately consumed and have been linked to environmental debate regarding habitat degradation from the harvesting of palm oil, which is sometimes used as a qualityenhancing ingredient in shampoos. Palm oil is associated with deforestation, species extinction, and aboriginal rights violations (Abdullah, Salamatinia, Mootabadi, \& Bhatia, 2009; Tan, Lee, Mohamed, \& Bhatia, 2009).

\subsection{Procedure}

After being presented with the same self-concept clarity measure $(\alpha=0.84)$ and filler tasks as in Study 1a, respondents were presented with a short vignette describing a standard and a green brand of shampoo (see Appendix C). The vignettes indicated to participants whether they had been assigned to a choice of the standard or the green product. After reading which brand they chose, participants read in the price promotion condition, "You only made this choice because 
the green brand (the standard brand) was offered at a discounted price." In the no price promotion condition, no such sentence was included.

As the dependent variable, we assessed consumer value directly, using a 1-item measure that asked respondents to indicate the "overall value of the chosen product, considering what is given up and what is received when choosing this product?" on a 7-point Likert scale (1 very poor value -7 very good value). Respondents completed some further scales including demographic questions.

\subsection{Study 4 results and discussion}

\subsubsection{Manipulation checks}

Prior to the main analysis, we checked whether price promotions did indeed reduce positive selfsignals from choices. To this end, we regressed an index of the five self-attributions $(\alpha=0.78)$ on assigned choice $($ standard $=-1$, green $=1)$, price promotion (no price discount $=-1$, price promotion $=1$ ), and their interaction. Results again confirm that assigned choices of the green product are associated with a significantly stronger positive self-signal than choices of the standard product $(\mathrm{b}=0.317, \mathrm{t}(1013)=8.79, \mathrm{p}<.001 ; \mathrm{M}(\mathrm{grn} \mid \mathrm{std})=5.22$ vs. 4.59). Price promotions significantly reduce the strength of positive self-signals from choices $(b=-0.103, t$ $(1013)=-2.85, \mathrm{p}=.004 ; \mathrm{M}($ no_promo $\mid$ promo $)=5.01$ vs. 4.80$)$. The interaction effect between assigned choice and price promotions is non-significant $(\mathrm{b}=-0.049, \mathrm{t}(1013)=-1.35, \mathrm{p}=.176)$. Hence, given the significant main effects, regardless of price promotions being offered, an assigned choice of the green product triggers stronger positive self-signals than an assigned choice of the standard product (no price promotions: $M($ grn $\mid$ std) $=5.37$ vs. 4.64; price promotions: $\mathrm{M}(\mathrm{grn} \mid \mathrm{std})=5.07$ vs. 4.53$)$, albeit at a lower level for the green product when price 
promotions are introduced $(b=-0.151, t(502)=-3.27, \mathrm{p}=.001 ;$ Mgreen_reg $=5.37 \mathrm{vs}$. Mgreen_discount $=5.07$ ).

\subsubsection{Effect of price promotions on consumer value}

We regressed consumer value on assigned choice ( standard $=-1$, green $=1$ ), price promotion (no price discount $=-1$, price promotion $=1$ ), mean-centered self-concept clarity, and all interactions among them. The main effects of green over standard assigned choice and selfconcept clarity are significant (assigned choice: $\mathrm{b}=0.202, \mathrm{t}(1009)=4.89, \mathrm{p}<.001$; self-concept clarity: $\mathrm{b}=0.212, \mathrm{t}(1009)=6.30, \mathrm{p}<.001)$. There is no significant main effect of price promotions $(b=0.048, t(1009)=1.171, p=.242)$. Importantly, the three-way interaction between assigned choice, discount, and self-concept clarity is significant and in line with our theorizing $(\mathrm{b}=0.067, \mathrm{t}(1009)=1.98, \mathrm{p}=.048)$ but no other interaction effect is significant.

Decomposing the interaction, in the condition without price promotions, there is a significant simple effect of assigned choice of the green brand (green $=1$, standard $=0$ ), at the mean level of self-concept clarity $(b=0.487, t(499)=4.23, p<.001)$, a direct effect of selfconcept clarity $(b=0.354, t(499)=5.26, p<.001)$, and a significant negative assigned choice $\times$ self- concept clarity interaction $(b=-0.229, \mathrm{t}(499)=-2.39, \mathrm{p}=.017)$, such that consumers with relatively low levels of self- concept clarity derive incrementally more consumer value from a choice of the green over the standard brand than consumers with relatively high levels of selfconcept clarity (Fig. 7). The Johnson and Neyman (1936) technique reveals a significant incremental gain in consumer value for an assigned choice of the green relative to an assigned choice of the standard brand for any value below 0.89 units of the mean of self-concept clarity $($ at $\mathrm{p}<.05)$. For any larger value, there is no significant difference in consumer value for assigned choices of the green over the standard product. 
Consistent with our predictions, such effects were not observed for the price promotion condition: While there is a significant simple effect of assigned choice of the green over the standard brand $(\mathrm{b}=0.310, \mathrm{t}(510)=2.62, \mathrm{p}=.009)$ and a direct effect of self- concept clarity $(\mathrm{b}=$ $0.167, \mathrm{t}(510)=2.40, \mathrm{p}=.017)$, there is no significant interaction effect with self-concept clarity $(b=0.037, t(510)=0.39, p=.699)$. That is, when discounts are offered, there is no significant difference between consumers with relatively high and low self-concept clarity in the value they derive from a green versus a standard brand. This finding is consequential because when price promotions reduce the self-diagnosticity of choices, particularly for consumers with low selfconcept clarity, the interaction effect should be reduced as well.

In order to further facilitate the interpretation of these findings, we plotted the simple effects of a green over a standard assigned choice on consumer value that emerged in both conditions (Fig. 7; see also Spiller et al., 2013). The plot illustrates the notion that particularly consumers with lower levels of self-concept clarity are affected by a crowding-out of self-signals through price promotions as the value added they gain through a choice of a green product without price discount is most noticeable. By contrast, consumers with relatively high levels of self-concept clarity remain relatively unaffected by the crowding-out of the self-signal attesting to them deriving little incremental value of an assigned green relative to an assigned standard choice even in no discount situations.

\section{Insert Figure 7 about here}

9. Study 5: Self-signaling for consumers with high self-concept clarity

The previous studies provide converging evidence for a joint effect of self-signals from comparative choices and self-concept clarity on consumer value, such that positive self-signals from privately consumed green products lead to incrementally higher consumer value for 
consumers with relatively low self-concept clarity but not significantly so for those with relatively high levels of self-concept clarity. This joint effect occurs for consumers with relatively low self-concept clarity because they gain incremental value from perceived selfconcept alignment - a state that is construed from the perception that a self-signal is aligned with the consumer's self-concept. Therefore, marketers might logically ask how they can also increase consumer value of privately consumed green products for customers with relatively high levels of self-concept clarity. The mechanism we have identified as underlying self-signaling suggests a possible solution. Managers might be able to increase consumer value by framing a choice as an opportunity for consumers to discover new, positive aspects about their own selfs. Such framing should lead consumers with relatively high levels of self-concept clarity to consider and process what the choice reveals about their selfs rather than that they 'freeze on' their internal trait knowledge. As a consequence, the self-information associated with a choice should be rendered relevant to these consumers. For consumers with relatively low self-concept clarity, the benefit of such framing might be small be- cause these consumers already view the regular choice as an opportunity to acquire new self-knowledge. The primary objective of Study 5 is thus to test the notion that self-signaling can be 'switched on' even for those consumers with relatively high levels of self-concept clarity when a choice is framed as an opportunity to learn new positive underlying dispositions.

\subsection{Participants}

We recruited participants from the United States through Amazon Mechanical Turk (Mturk) in exchange for a nominal payment. We analyzed only responses of participants who passed an attention check (correctly reporting the assigned choice). We omitted responses from twenty-four participants who were not diligent in completing the self-concept clarity manipulation (e.g., 
copying and pasting our instruction texts). We obtained usable responses from one-thousand and twenty-six participants $($ male $=41.7 \%$, mean age $=38.52)$. Mean income was between $\$ 40,000$ and $\$ 59,000$ USD per year.

\subsection{Study design and procedure}

We employed a 2 (assigned choice: green vs. standard) $\times 2$ (choice framing: regular vs. learning) $\times 2$ (high vs. low self-concept clarity) between-participants design. We manipulated self-concept clarity before randomly allocating participants to one of the experimental conditions. We relied on the same task as used in Study 2, such that participants were prompted to consider a time when they felt respectively clear or conflicted about their sense of self, followed by a request to describe this reflection in detail. Respondents were then presented with the same vignette as in Study 4, describing two bottles of shampoo (see Appendix C). The vignettes indicated to participants whether they chose the standard or the green product. In the learning condition, a sentence was added at the end of the vignette saying, "Remember that through a choice of a green over a standard brand [standard over a green brand] of shampoo you might learn something new about yourself - that you are sympathetic and compassionate [selfish and unsympathetic]." In the regularly framed choice condition, no such sentence was included. The attention check was included after the vignette. As the dependent variable, we assessed consumer value directly, using the same measure as in Study 4. We asked respondents to indicate the "overall value of the chosen product, considering what is given up and what is received when choosing this product?" on a 7-point Likert scale (1 very poor value - 7 very good value).

\subsection{Study 5 results and discussion}

We regressed consumer value on assigned choice ( standard $=-1$, green $=1$ ), choice framing 
$($ regular $=-1$, learning $=1)$, manipulated self-concept clarity $($ low $=-1$, high $=1)$, and all interactions among them. The main effect of green over standard choice is significant (assigned choice: $\mathrm{b}=0.262, \mathrm{t}(1018)=5.83, \mathrm{p}<.001)$, whereas there are no significant main effects of choice framing and manipulated self-concept clarity (choice framing: $b=-0.014, t(1018)=$ $-0.319, p=.750$; self-concept clarity: $b=0.014, t(1018)=0.322, p=.748)$. Importantly, the three-way interaction between assigned choice, choice framing, and self-concept clarity is significant and in line with our theorizing $(b=-0.092, \mathrm{t}(1018)=-2.04, \mathrm{p}=.042)$. In addition, there is a significant two-way interaction between assigned choice and choice framing $(b=$ $0.150, \mathrm{t}(1018)=3.33, \mathrm{p}=.001)$ but no other interaction effect is significant $($ at $\mathrm{p}<.05)$.

Next, we decomposed the three-way interaction into the high and low self-concept clarity condition. In the high self-concept clarity condition, there is no significant direct effect of choice framing on consumer value $(\mathrm{b}=-0.014, \mathrm{t}(505)=-0.215, \mathrm{p}=.830 ; \mathrm{M}($ regl|lern $)=4.74$ vs. 4.71$)$, and a significant overall positive effect of assigned choice of the green brand on consumer value $(\mathrm{b}=0.238, \mathrm{t}(505)=3.63, \mathrm{p}<.001)$, such that an assigned choice of the green brand $(\mathrm{Mgrn}=$ 4.97) leads to higher consumer value than an assigned choice of the standard brand ( $M_{\text {std }}=$ 4.49). Importantly, this effect is moderated by the framing of the choice as indicated by a significant interaction effect between assigned choice and choice framing $(b=0.242, t(505)=$ $3.69, \mathrm{p}<.001)$. Hence, consumers with relatively high self-concept clarity gain incrementally more value from an assigned choice of the green product when the choice is framed as an opportunity to learn new things about one's own self (learning condition: $\mathrm{M}$ (grn|std) $=5.19$ vs. 4.23) but not significantly so when there is just a regular choice (regular condition: $\mathrm{M}(\mathrm{grn} \mid \mathrm{std})=$ 4.74 vs. 4.75$)$. Hence, self-signaling can be 'switched on' for consumers with relatively high levels of self-concept clarity when a choice is framed as an opportunity to learn new positive 
underlying dispositions.

In the low self-concept clarity condition, there is a significant direct effect of assigned choice of the green over the standard brand on consumer value $(b=0.287, t(513)=4.65, p<$ $.001)$, such that consumers with relatively low self-concept clarity derive significantly more consumer value from an assigned choice of the green brand $(\mathrm{Mgrn}=5.04)$ than from a standard brand $\left(M_{s t d}=4.47\right)$. The direct effect of choice framing $(b=-0.015, t(513)=-0.236, p=.813$; $\mathrm{M}(\mathrm{reg}||$ lern $)=4.77$ vs. 4.74$)$, and the interaction effect between assigned choice and choice framing $(\mathrm{b}=0.058, \mathrm{t}(513)=0.943, \mathrm{p}=.346$; learning condition: $\mathrm{M}(\mathrm{grn} \mid \mathrm{std})=5.09$ vs. 4.40; regular condition: $\mathrm{M}(\mathrm{grn} \mid \mathrm{std})=5.00$ vs. 4.54$)$ on consumer value are both non-significant. This finding suggests that explicitly framing the choice as an opportunity to learn will have very little effect on consumers with relatively low self-concept clarity, presumably because this framing merely explicates what is already obvious for consumers with relatively low self-concept clarity; see Fig. 8.

Insert Figure 8 about here

Thus consumers with high self-concept clarity can derive self-signaling value from a choice when it is framed as an opportunity to acquire new knowledge about the self. Through such a framing, consumer value can be increased for privately consumed green products even for consumers with high self-concept clarity. The results of Study 5 also provide an interesting implication for decision makers - a point we return to in the overall discussion.

\section{General discussion}

Despite consumers' lay beliefs that green products are less effective or of lower quality, some consumers nonetheless derive positive incremental utility from choices of green products 
(Carrington et al., 2014; Hughner et al., 2007; Magnusson et al., 2003; McEachern \& McClean, 2002). We find that self-signaling could plausibly underlie this effect. Across six studies, we explore how and when self-signals inferred from comparative choices of green versus standard products influence consumer value from choice. We specifically focus on green products that are consumed in private as opposed to products consumed in public, on which a majority of previous work has focused (e.g., Griskevicius et al., 2010; Guthman, 2002; van der Wal, Van Horen, \& Grinstein, 2016).

We find that the effect of positive self-signals from a comparative choice of a green product on consumer value depends on structural aspects of the consumer's self-concept, that is, on the level of a consumer's self-concept clarity. Consumers with relatively low levels of selfconcept clarity derive self-diagnostic value from private green consumption, such that they derive incremental value from self-confirmatory information from choosing a green product over a standard product. For these consumers, this 'ego-utility' can be strong enough to outweigh perceived or actual quality disadvantages of products with green features com- pared to their conventional counterparts. By contrast, consumers with relatively high levels of self-concept clarity do not derive significant incremental value from choosing a green product over a standard product but also appear to be affected less by a negative self-signal. Yet these consumers can be made susceptible to the symbolic self-inferential benefits that privately consumed green products provide when the choice is framed as an opportunity to learn new positive aspects about their own self. Further, when choice context dilutes the self-diagnosticity of choices (e.g., in case of non-feasibility of a choice due to potential allergic re- action), consumer value tends to be lower for green products even for consumers with low self-concept clarity compared to when selfdiagnosticity from choice of privately consumed green products remains intact. The joint effect 
of self-signals and self-concept clarity emerges whether self-concept clarity is self-reported or manipulated, and it occurs for hypothetical as well as real choices. A potential explanation for the joint effect is incremental value resulting for consumers with relatively low values of selfconcept clarity to a much greater extent than for consumers with relatively high self-concept clarity from the perception that a self- signal is aligned with a consumer's self-concept.

Presumably this occurs because consumers with low self-concept clarity have higher epistemic needs and therefore react more favorably towards self-relevant information than consumers with high self- concept clarity.

\subsection{Theoretical contributions}

The present research advances current self-signaling accounts by providing a path towards a better understanding of the psychology that underpins self-signaling. With this study, we move beyond previous perspectives on self-signaling, which have not fully accounted for the role played by the self-concept in the relationship between self-signals and consumer value (e.g., Dhar \& Wertenbroch, 2012; Dubé et al., 2017; Savary et al., 2015). By incorporating selfconcept clarity and perceived self-concept alignment into an integrated self-signaling model, we are able to flesh out a potential mechanism underlying self-signaling that can account for how and when self-signals interact with the self to ultimately impact consumer value. We now understand that incremental consumer value derived from self-signals systematically differs between individuals with high versus low self-concept clarity and not simply as a function of the symbolic features of the choice options (e.g., Dubé et al., 2017) or features of the choice context itself (e.g., Dhar \& Wertenbroch, 2012). This understanding is important because it provides a more refined and nuanced perspective on self-signaling, leading us to appreciate that structural aspects of the self can act as an important boundary condition to the phenomenon of self- 
signaling.

Second, we not only provide insights into the when but also seek to open a door towards an understanding of how self- signaling might function as a process. More specifically, we show that consumers with relatively low levels of self-concept clarity derive significant incremental value from self-information confirming self-qualities, leading to a positive, incremental effect on consumer value from a comparative choice. It is as if these consumers were more morally impressed or disappointed by their green choices than consumers with relatively high selfconcept clarity (cf. Prelec \& Bodner, 2003), which has an immediate impact on the level of consumption value they derive from comparative choices of green products. By contrast, those with relatively high levels of self-concept clarity derive only very little incremental consumer value from choosing a green product over a standard product because their self-beliefs are relatively clearly defined. Self-information that verifies their self-concept might simply be less novel or less relevant for them. As such, for consumers with higher levels of self-concept clarity, positive self-information exerts little impact on the value derived from a comparative choice of green products. This finding suggests that being chronically uncertain about one's own self may not only lead consumers to actively seek out diagnostic choices (Savary \& Dhar, 2020) but that the appraisal process of self-signals itself systematically varies between high and low selfconcept clarity consumers.

With its focus on self-signals, our work differs from research on the self-expression function of consumption choices, i.e., choices made mainly for the purpose of signaling aspects of the consumer's self to others (e.g., Amaldoss \& Jain, 2005; Berger \& Heath, 2007; Berger \& Ward, 2010; Rozenkrants et al., 2017; Twitchell, 2002). Consumer research has generally acknowledged the notion that consumers are inclined to signal to others their knowledge of 
culture, taste, style, or that one is green or ethical (Griskevicius et al., 2010; Guthman, 2002; Noppers et al., 2014). While this work has certainly been insightful, the type of signaling is, however, related to instilling or maintaining a desired image in other consumers, whereas selfsignaling is related to uncovering or reaffirming one's own preferences and predispositions (Loewenstein \& Schkade, 1999; Prelec \& Bodner, 2003). The effectiveness of other-signals is hence logically conditional on the visibility of the consumption itself whereas the effectiveness of self-signaling does not inherently depend on the visibility of choices and hence can be effective for privately consumed products as well. As such, our self-signaling account may have significance for explaining the value added through choices of green products that are consumed in private.

In fact, we have empirically contrasted our self-signaling account with other-signaling, in the gestalt of conspicuous green consumption, and find that the add-on in consumer value for choices of green products relative to choices of the conventional counterpart disappeared because the positive self-signal from these choices was diluted by the other-signal. This finding is in line with a key assumption of self-perception theory (Bem, 1972), namely that inferring underlying dispositions from an external behavior, such as a choice, is the same irrespective of whether the inference relates to someone else's or one's own dispositions (Bem, 1972; Prelec \& Bodner, 2003). Simply put: just as we discount someone else's behavior for being driven solely by the motive to impress others, so too we may discount our own behavior (Prelec \& Bodner, 2003). As such, our findings imply that the self-diagnosticity of choices appears to be discounted when other external motivations are present (e.g., other-signals, price discounts) that can serve as plausible alternative explanations for the choice to the consumer's self.

Our work differs from more recent research that has begun to link self-concept clarity 
with conspicuous consumption (Rozenkrants et al., 2017). This work found that consumers with low self-concept clarity have a preference for polarizing products that are publicly consumed, such as outfits and style of shoes (Rozenkrants et al., 2017). Yet it leaves unexamined whether this preference would persist when self-signaling rather than other-signaling motives are more salient, such as in the case of privately consumed necessities. It therefore does not shed light on self-signaling per se.

We further note that our work differs from previous research that has linked the consumer's self to choices of green products. While this work has predominantly focused on single salient aspects of the consumer's identity, such as, for example, moral identity (e.g., Reed, Aquino, \& Levy, 2007), we consider more holistically the structural aspect of the consumer's self, which can be assumed to be chronically, as opposed to contextually relevant to the consumer's behavior (cf. Campbell et al., 1996), and investigate how the value added from choices of green products depends on the qualities of this structural aspect.

\subsection{Managerial implications}

Our findings have implications predominantly for the marketing of privately consumed green products. Since there is an in- creasing demand by customers for green products that are consumed in private, such as toiletries, food ingredients, or house- hold cleaners, firms seek ways to respond to this market trend (Bird \& Hughes, 1997; Brécard, Hlaimi, Lucas, Perraudeau, \& Salladarré, 2009). Our findings suggest that green products tend to be associated with a willingness to pay a price premium over standard products. This price premium stems from the unique morally-related symbolic benefits green products can offer - to signal positive traits to the consumer's own self. Importantly, these signaling benefits are significant enough to thwart imagined or actual quality-related disadvantages compared to standard products. In order for 
companies to benefit from an in- creased willingness to pay, our findings suggest that these signaling benefits need to materialize for the consumer. For this to happen, the choice has to have the potential to reveal to the consumer an underlying positive disposition, i.e., it has to imply some diagnosticity for the self. Hence, at the moment of choice, the self-inferential benefits of privately consumed green products should be salient. An example is the Swedish company Humble Co., which is manufacturing and selling tooth and dish brushes made from sustainably grown bamboo. On the packages of the brushes they inform potential consumers about how plastic, including plastic brushes, pollutes oceans and landfills, which should render self-signaling advantages from choosing a bamboo toothbrush instead of a conventional counterpart highly salient. Consumers are likely to interpret this choice as evidence of his or her environmental conscientiousness. Note that Humble Co. prices the toothbrush at a significant mark-up com- pared to regular toothbrushes.

Since primarily consumers with low self-concept clarity derive value from self-signals associated with choices of green products and accordingly exhibit high willingness to pay, marketers might logically ask how they can also increase willingness to pay for privately consumed green products for customers with high levels of self-concept clarity. The mechanism we have identified as underlying our self-signaling account suggests a possible solution. Since consumers with low self-concept clarity do not see the contents of their self-concept as clearly (Campbell et al., 1996), they appear to react more favorably to the positive self- information contained in a self-signal. Hence, as findings from Study 5 indicate, framing a choice as an opportunity for consumers to discover new, positive aspects about their own selfs can increase consumer value for consumers with relatively high self- concept clarity alike. Such framing will likely lead these consumers to consider and process what the choice reveals about their self 
rather than that they 'freeze on' their internal trait knowledge, and the self-information associated with a choice will be rendered relevant for them. Thus managers might explicitly promote a green product by framing a choice as an opportunity to learn or discover new, positive aspects about the consumer's own self. This can be accomplished by modifying the traditional marketing- mix elements, including information provided in promotions and on packaging. For instance, claims such as 'searching for unique, authentic, green experiences?' might be useful in this regard. Brand names might also be used as explicit cues. One example is the Italian label "The Green Experience."

In addition, our results indicate that products with self-signaling benefits appear to be particularly attractive to consumers when the clarity of their self-concept is challenged - for instance, when they experience significant transition phases in their lives (e.g., during the phase of getting married or after graduation) or when the clarity is challenged at the level of a single incident - for instance, offering the consumer the opportunity to offset the carbon footprint of a long-distance flight through a nominal payment.

However, not all choices of green over standard products are viewed as self-diagnostic. Regular price discounts appear to dilute the self-inferential value of non-conspicuous products specifically for consumers with relatively low self-concept clarity. While such dilution might be beneficial in case of negative self-signals, it might be advisable for decision-makers to frame a price dis- count such that it would allow consumers to perpetuate positive self-signals. For instance, when a discount is framed as 'lower introductory price,' the customer might still construe the choice as diagnostic for a positive underlying disposition rather than attributing the choice to the reward associated with the lower price. Similarly, discounting peripheral services surrounding the transaction instead of the products itself appears useful in this regard - for 
instance, offering free delivery instead of direct discounts.

\subsection{Limitations and future research}

Conceptually self- and other-signaling involve two different types of rewards for the consumer: rewards from instilling a de- sired image in other customers and rewards from addressing epistemic needs regarding oneself. Through our empirical confrontation in Study 1a, we found some evidence that other-signals can dilute positive self-signals from comparative green choices and hence diminish value associated with these choices. While such between-concept confrontations have been criticized because they may lead to overly fragmented theories (Tetlock \& Manstead, 1985), we believe that this empirical confrontation has been fruitful in demonstrating that our self-signaling account can have merit for explaining consumer value associated with green products that are consumed in private, such as green cleaning products or toiletries, and some types of green cooking ingredients. There might be cases, however, where self- and other-signals interact in functional ways because they are not incompatible with each other - a theme future scholars may wish to explore.

In this study, we have fleshed out conditions under which consumers derive incremental consumption value from self-signals associated with a choice of a product with green features over a conventional product. The extent to which the symbolic benefits of these choices can overcompensate actual or perceived quality disadvantages and thus boost relative consumption value may, however, be moderated by how severe the quality disadvantages are felt to be or by how severe the negative environmental impact of the standard options is judged to be by the consumer. For instance, perceived quality disadvantages of green products have been found to be particularly strong in product categories in which consumers value strength-related benefits, such as car cleaning products (Luchs, Naylor, Irwin, \& Raghunathan, 2010). 
We believe that similar effects to these uncovered herein might occur in a number of other contexts, including ethnicity-based and adventure-based options, as well as services related to mobile fitness tracking and gendered products. For example, individuals might re-affirm a gender identity through self-signaling by choosing to buy a product that aligns with a particular heteronormative gender. However, more research is needed to examine whether the effects would indeed be generalizable to these other contexts. Future scholars may wish to explore consumer contexts other than green consumption contexts with non-comparative choices.

Furthermore, it would be interesting to investigate how the subjectively felt importance of an aspects of the consumer's self impacts self-signaling (Reed, Forehand, Puntoni, \& Warlop, 2012). For instance, previous work found that subjective importance should lead consumers to engage in behaviors associated with this aspect of their self-concept (e.g., Leung, Paolacci, \& Putoni, 2018) - yet the occurrence of this behavior might vary as a function of self-concept clarity. Consumers for whom being an environmentalist is crucial but who are not certain about this particular self-aspect might feel a heightened need to signal this self-view to themselves. Consumers who feel certain and confident about this aspect might have lower self- signaling needs.

While our theorizing mainly focuses on positive self-signals from choices of green products as a function of self-concept clarity, the results further suggest that with decreasing levels of self-concept clarity, the value consumers derive from a choice of a conventional over a green product decreases incrementally. As alluded to, this finding might imply that consumers with low self-concept clarity might derive stronger negative self-signaling value from a choice of a conventional product (Bodner \& Prelec, 2003; Prelec \& Bodner, 2003). More research is needed to examine the consequences of negative self-signals more specifically. 
Finally, it is of note that our work draws on the notion that consumer choice is essentially comparative in nature, i.e., that consumers evaluate options relative to other options (Kahneman \& Miller, 1986; Savary et al., 2015; Schwarz \& Bless, 1992). On this basis, we demonstrate that people make self-inferences based on comparative choices of green versus standard products. Yet comparative choices are not a necessary prerequisite for self-signals to occur (cf. Dubé, Luo, \& Fang, 2017; Savary et al., 2015). For example, existing work shows that people derive negative self-signals from deciding not to donate $\$ 5$ in response to a charitable appeal (Savary et al., 2015). 


\section{References}

Abdullah, A. Z., Salamatinia, B., Mootabadi, H., \& Bhatia, S. (2009). Current status and policies on biodiesel industry in Malaysia as the world's leading producer of palm oil. Energy Policy, 37(12), 5440-5448. https://doi.org/10.1016/j.enpol.2009.08.012.

Alloy, L. B., Abramson, L. Y., \& Viscusi, D. (1981). Induced mood and the illusion of control. Journal of Personality and Social Psychology, 41(6), 1129.

Alwitt, L. F., \& Pitts, R. E. (1996). Predicting purchase intentions for an environmentally sensitive product. Journal of Consumer Psychology, 5(1), 49-64.

Amaldoss, W., \& Jain, S. (2005). Pricing of conspicuous goods: A competitive analysis of social effects. Journal of Marketing Research, 42(1), 30-42.

Amir, O., Ariely, D., \& Carmon, Z. (2008). The dissociation between monetary assessment and predicted utility. Marketing Science, 27(6), 1055-1064.

Andrews, M., Luo, X., Fang, Z., \& Aspara, J. (2014). Cause marketing effectiveness and the moderating role of price discounts. Journal of Marketing, 78(6), 120-142.

Ariely, D., Loewenstein, G., \& Prelec, D. (2000). Coherent arbitrariness: Duration-sensitive pricing of hedonic stimuli around an arbitrary anchor. MIT mimeo. Aronson, E. (1969). The theory of cognitive dissonance: A current perspective. Advances in Experimental Social Psychology, 4, 1-34.

Baca-Motes, K., Brown, A., Gneezy, A., Keenan, E. A., \& Nelson, L. D. (2013). Commitment and behavior change: Evidence from the field. Journal of Consumer Research, 39 (5), 1070 1084. https://doi.org/10.1086/667226.

Bem, D. J. (1972). Self-perception theory. Advances in Experimental Social Psychology, 6, 162.

Bénabou, R., \& Tirole, J. (2000). Self-confidence: Intrapersonal strategies. Princeton working paper.

Bénabou, R., \& Tirole, J. (2004). Willpower and personal rules. Journal of Political Economy, 112(4), 848-886.

Bénabou, R., \& Tirole, J. (2006). Incentives and prosocial behavior. American Economic Review, 96(5), 1652-1678. https://doi.org/10.1257/aer.96.5.1652.

Bennett, A., \& Chakravarti, A. (2008). Self and social signaling explanations for consumption of CSR-associated products. Advances in Consumer Research, 35, 1010-1011. 
Berger, J., \& Heath, C. (2007). Where consumers diverge from others: Identity signaling and product domains. Journal of Consumer Research, 34(2), 121-134.

Berger, J., \& Ward, M. (2010). Subtle signals of inconspicuous consumption. Journal of Consumer Research, 37(4), 555-569. https://doi.org/10.1086/655445.

Bird, K., \& Hughes, D. R. (1997). Ethical consumerism: The case of "Fairly-Traded" coffee. Business Ethics: A European Review, 6(3), 159-167.

Bodner, R., \& Prelec, D. (1997). The diagnostic value of actions in a self-signaling model. MIT mimeo, January.

Bodner, R., \& Prelec, D. (2003). Self-signaling and diagnostic utility in everyday decision making. In I. Brocas, \& J. Carrillo (Eds.), The psychology of economic decisions. Vol. 1. (pp. 105-126). London, UK: Oxford University Press.

Bolton, R. N., \& Drew, J. H. (1991). A multistage model of customers' assessments of service quality and value. Journal of Consumer Research, 17(4), 375-384.

Brécard, D., Hlaimi, B., Lucas, S., Perraudeau, Y., \& Salladarré, F. (2009). Determinants of demand for green products: An application to eco-label demand for fish in Europe. Ecological Economics, 69(1), 115-125.

Brewer, M. B. (1991). The social self: On being the same and different at the same time. Personality and Social Psychology Bulletin, 17(5), 475-482.

Buhrmester, M., Kwang, T., \& Gosling, S. D. (2011). Amazon's Mechanical Turk: A new source of inexpensive, yet high-quality, data? Perspectives on Psychological Science, 6, 3-5.

Campbell, J. D., Trapnell, P. D., Heine, S. J., Katz, I. M., Lavallee, L. F., \& Lehman, D. R. (1996). Self-concept clarity: Measurement, personality correlates, and cultural boundaries. Journal of Personality and Social Psychology, 70(1), 141.

Carrington, M. J., Neville, B. A., \& Whitwell, G. J. (2014). Lost in translation: Exploring the ethical consumer intention-behavior gap. Journal of Business Research, 67(1), 2759-2767.

Chandler, J., Mueller, P., \& Paolacci, G. (2014). Nonnaïveté among Amazon Mechanical Turk workers: Consequences and solutions for behavioral researchers. Behavior Research Methods, 46, 112-130.

Cohen, J. (1988). Statistical power analysis for the behavioral science. New York: Lawrence Erlbaum Associates.

Darke, P. R., \& Chung, C. M. (2005). Effects of pricing and promotion on consumer perceptions: It depends on how you frame it. Journal of Retailing, 81(1), 35-47. 
De Dreu, C. K., \& van Knippenberg, D. (2005). The possessive self as a barrier to conflict resolution: Effects of mere ownership, process accountability, and self-concept clarity on competitive cognitions and behavior. Journal of Personality and Social Psychology, 89(3), 345.

DeMarree, K. G., \& Morrison, K. R. (2012). What do I think about who I am? Metacognition and the self-concept. In B. P., \& D. K. G. (Eds.), Social metacognition (pp. 103-119). New York: Psychology Press.

Dhar, R., \& Wertenbroch, K. (2012). Self-signaling and the costs and benefits of temptation in consumer choice. Journal of Marketing Research, 49(1), 15-25.

DiDonato, T. E., \& Jakubiak, B. K. (2016). Sustainable decisions signal sustainable relationships: How purchasing decisions affect perceptions and romantic attraction. The Journal of Social Psychology, 156(1), 8-27.

Dubé, J. -P., Luo, X., \& Fang, Z. (2017). Self-signaling and prosocial behavior: A cause marketing experiment. Marketing Science, 36(2), 161-186.

Festinger, L. (1957). A theory of cognitive dissonance. Stanford, CA: Stanford University Press.

Gleim, M. R., Smith, J. S., Andrews, D., \& Cronin, J. J. (2013). Against the green: A multimethod examination of the barriers to green consumption. Journal of Retailing, 89 (1), 44-61.

Goel, G., \& Kaur, S. (2012). A study on chemical contamination of water due to household laundry detergents. Journal of Human Ecology-New Delhi, 38(1), 65.

Goldstein, N. J., Cialdini, R. B., \& Griskevicius, V. (2008). A room with a viewpoint: Using social norms to motivate environmental conservation in hotels. Journal of Consumer Research, 35(3), 472-482.

Golin, S., Terrell, F., \& Johnson, B. (1977). Depression and the illusion of control. Journal of Abnormal Psychology, 86(4), 440.

Golin, S., Terrell, F., Weitz, J., \& Drost, P. L. (1979). The illusion of control among depressed patients. Journal of Abnormal Psychology, 88(4), 454.

Goodman, Joseph K., \& Lim, Sarah (2018). When Consumers Prefer to Give Material Gifts Instead of Experiences: The Role of Social Distance. Journal of Consumer Research, Vol. 45 (2). (pp. 365-382), 365-382.

Green, T., \& Peloza, J. (2014). Finding the right shade of green: The effect of advertising appeal type on environmentally friendly consumption. Journal of Advertising, 43 (2), 128-141. https://doi.org/10.1080/00913367.2013.834805. 
Griskevicius, V., Tybur, J. M., \& Van den Bergh, B. (2010). Going green to be seen: Status, reputation, and conspicuous conservation. Journal of Personality and Social Psychology, 98(3), 392.

Guthman, J. (2002). Commodified meanings, meaningful commodities: Re-thinking productionconsumption links through the organic system of provision. Sociologia Ruralis, 42(4), 295-311.

Haws, K. L., Winterich, K. P., \& Naylor, R. W. (2013). Seeing the world through GREEN-tinted glasses: Green consumption values and responses to environmentally friendly products. Journal of Consumer Psychology, 24(3), 336-354. https://doi.org/10.1016/j.jcps.2013.11.002.

Hayes, A. F. (2013). Introduction to mediation, moderation, and conditional process analysis. New York: Guilford.

Hayes, A. F., \& Matthes, J. (2009). Computational procedures for probing interactions in OLS and logistic regression: SPSS and SAS implementations. Behavior Research Methods, 41(3), 924-936.

Higgins, E. T. (1987). Self-discrepancy: A theory relating self and affect. Psychological Review, 94(3), 319.

Higgins, E. T., \& Rholes, W. S. (1978). "Saying is believing": Effects of message modification on memory and liking for the person described. Journal of Experimental Social Psychology, 14(4), 363-378.

Holman, R. H. (1981). Product use as communication: A fresh appraisal of a venerable topic. In B. M. Enis, \& K. J. Roering (Eds.), Review of marketing (pp. 106-119). Chicago: AMA.

Hughner, R. S., McDonagh, P., Prothero, A., Shultz, C. J., \& Stanton, J. (2007). Who are organic food consumers? A compilation and review of why people purchase organic food. Journal of Consumer Behaviour, 6(2-3), 94-110.

Janssen, M. A., \& Jager, W. (2002). Stimulating diffusion of green products. Journal of Evolutionary Economics, 12(3), 283-306.

Johnson, P. O., \& Fay, L. C. (1950). The Johnson-Neyman technique, its theory and application. Psychometrika, 15(4), 349-367.

Johnson, P. O., \& Neyman, J. (1936). Tests of certain linear hypotheses and their application to some educational problems. Statistical Research Memoirs, 1, 57-93.

Kahneman, D., \& Miller, D. T. (1986). Norm theory: Comparing reality to its alternatives. Psychological Review, 93(2), 136-153 
Kidwell, B., Farmer, A., \& Hardesty, D. M. (2013). Getting liberals and conservatives to go green: Political ideology and congruent appeals. Journal of Consumer Research, 40(2), 350-367.

Leung, E., Paolacci, G., \& Putoni, S. (2018). Man versus machine: Resisting automation in identity-based consumer behavior. Journal of Marketing Research, 55(6), 818-831.

Lin, Y. -C., \& Chang, C. -C. A. (2012). Double standard: The role of environmental consciousness in green product usage. Journal of Marketing, 76(5), 125-134.

Loewenstein, G., \& Schkade, D. (1999). Wouldn't it be nice? Predicting future feelings. In D. Kahneman, E. Diener, \& N. Schwarz (Eds.), Well-being: The foundations of hedonic psychology (p. 85-105). Russell Sage Foundation.

Luchies, L. B., Finkel, E. J., McNulty, J. K., \& Kumashiro, M. (2010). The doormat effect: When forgiving erodes self-respect and self-concept clarity. Journal of Personality and Social Psychology, 98(5), 734-749. https://doi.org/10.1037/a0017838.

Luchs, M. G., Naylor, R. W., Irwin, J. R., \& Raghunathan, R. (2010). The sustainability liability: Potential negative effects of ethicality on product preference. Journal of Marketing, 74(5), 1831.

Magnusson, M. K., Arvola, A., Hursti, U. -K. K., Åberg, L., \& Sjödén, P. -O. (2003). Choice of organic foods is related to perceived consequences for human health and to environmentally friendly behaviour. Appetite, 40(2), 109-117.

McEachern, M. G., \& McClean, P. (2002). Organic purchasing motivations and attitudes: Are they ethical? International Journal of Consumer Studies, 26(2), 85-92.

McManus, T. C., \& Rao, J. M. (2015). Signaling smarts? Revealed preferences for self and social perceptions of intelligence. Journal of Economic Behavior \& Organization, 110(0), 106118. https://doi.org/10.1016/j.jebo.2014.12.009.

Meays, C., \& Nordin, R. (2013). Ambient water quality guidelines for Sulphate. British Columbia.

Mijović-Prelec, D., \& Prelec, D. (2010). Self-deception as self-signalling: A model and experimental evidence. Philosophical Transactions of the Royal Society of London B: Biological Sciences, 365(1538), 227-240. https://doi.org/10.1098/rstb.2009.0218.

Mittal, B. (2015). Self-concept clarity: Exploring its role in consumer behavior. Journal of Economic Psychology, 46, 98-110.

Monterosso, J. R., \& Luo, S. (2010). An argument against dual valuation system competition: Cognitive capacities supporting future orientation mediate rather than compete with visceral motivations. Journal of Neuroscience, Psychology, \& Economics, 3(1), 1-14. 
https://doi.org/10.1037/a0016827.

Newholm, T., \& Shaw, D. (2007). Studying the ethical consumer: A review of research. Journal of Consumer Behaviour, 6(5), 253-270.

Newman, G. E., Gorlin, M., \& Dhar, R. (2014). When going green backfires: How firm intentions shape the evaluation of socially beneficial product enhancements. Journal of Consumer Research, 41(3), 823-839.

Noppers, E. H., Keizer, K., Bolderdijk, J. W., \& Steg, L. (2014). The adoption of sustainable innovations: Driven by symbolic and environmental motives. Global Environmental Change, 25, $52-62$.

Oliver, R. L. (1993). Cognitive, affective, and attribute bases of the satisfaction response. Journal of Consumer Research, 20(3), 418-430.

Oliver, R. L. (1997). Satisfaction: A behavioral perspective on the customer. New York.

Omtzigt, D., \& Hendriks, A. W. (2004). Magnocellular involvement in flanked-letter identification relates to the allocation of attention. Vision Research, 44(16), 1927-1940.

Pedersen, L. H. (2000). The dynamics of green consumption: A matter of visibility? Journal of Environmental Policy \& Planning, 2(3), 193-210.

Prelec, D., \& Bodner, R. (2003). Self-signalling and self-control. Time and Decision: Economic and Psychological Perspectives of Intertemporal Choice (pp. 277-301). New York, NY: Russell Sage Press.

Quattrone, G. A., \& Tversky, A. (1984). Causal versus diagnostic contingencies: On selfdeception and on the voter's illusion. Journal of Personality and Social Psychology, 46(2), 237.

Reed, A., Aquino, K., \& Levy, E. (2007). Moral identity and judgments of charitable behaviors. Journal of Marketing, 71(1), 178-193.

Reed, A., Forehand, M. R., Puntoni, S., \& Warlop, L. (2012). Identity-based consumer behavior. International Journal of Research in Marketing, 29(1), 310-321.

Rozenkrants, B., Wheeler, S. C., \& Shiv, B. (2017). Self-expression cues in product rating distributions: When people prefer polarizing products. Journal of Consumer Research, 44, 759777.

Rucker, D. D., \& Galinsky, A. D. (2008). Desire to acquire: Powerlessness and compensatory consumption. Journal of Consumer Research, 35(2), 257-267.

Savary, J., \& Dhar, R. (2020). The uncertain self: How self-concept structure affects subscription 
choice. Journal of Consumer Research, 46(5), 887-903.

Savary, J., Goldsmith, K., \& Dhar, R. (2015). Giving against the odds: When tempting alternatives increase willingness to donate. Journal of Marketing Research, 52(1), 27-38.

Schlegel, R. J., Hicks, J. A., Arndt, J., \& King, L. A. (2009). Thine own self: True self-concept accessibility and meaning in life. Journal of Personality and Social Psychology, 96 (2), 473.

Schwarz, N., \& Bless, H. (1992). Scandals and the public's trust in politicians: Assimilation and contrast effects. Personality and Social Psychology Bulletin, 18(5), 574-579.

Sedikides, C., \& Strube, M. J. (1997). Self-evaluation: To thine own self be good, to thine own self be sure, to thine own self be true, and to thine own self be better. Advances in Experimental Social Psychology, 29, 209-269.

Sedikides, C., Gregg, A. P., Cisek, S., \& Hart, C. M. (2007). The I that buys: Narcissists as consumers. Journal of Consumer Psychology, 17(4), 254-257. https://doi.org/10.1080/10577400701542346.

Simonsohn, U., \& Loewenstein, G. (2006). Mistake\# 37: The effect of previously encountered prices on current housing demand. The Economic Journal, 116(508), 175-199.

Simonson, I., \& Drolet, A. (2004). Anchoring effects on consumers' willingness-to-pay and willingness-to-accept. Journal of Consumer Research, 31(3), 681-690.

Spiller, S. A., Fitzsimons, G. J., Lynch, J. G., Jr., \& McClelland, G. H. (2013). Spotlights, floodlights, and the magic number zero: Simple effects tests in moderated regression. Journal of Marketing Research, 50(2), 277-288.

Steg, L., \& de Groot, J. I. (2012). Environmental values. The Oxford Handbook of Environmental and Conservation Psychology (pp. 81-92). New York, NY: Oxford University Press.

Swann, W. B., Stein-Seroussi, A., \& Giesler, R. B. (1992). Why people self-verify. Journal of Personality and Social Psychology, 62(3), 392.

Tan, K. T., Lee, K. T., Mohamed, A. R., \& Bhatia, S. (2009). Palm oil: Addressing issues and towards sustainable development. Renewable and Sustainable Energy Reviews, 13(2), 420-427. https://doi.org/10.1016/j.rser.2007.10.001.

Tetlock, P. E., \& Manstead, A. S. (1985). Impression management versus intrapsychic explanations in social psychology: A useful dichotomy? Psychological Review, 92 (1), 59.

Thaler, R. (1985). Mental accounting and consumer choice. Marketing Science, 4(3), 199-214. 
Thibodeau, R., \& Aronson, E. (1992). Taking a closer look: Reasserting the role of the selfconcept in dissonance theory. Personality and Social Psychology Bulletin, 18(5), 591-602.

Twitchell, J. B. (2002). Living it up. New York, NY: Columbia University Press.

van der Wal, A. J., Van Horen, F., \& Grinstein, A. (2016). The paradox of 'Green to be Seen': green high-status shoppers excessively use (Branded) shopping bags. International Journal of Research in Marketing, 33(1), 216-219. https://doi.org/10.1016/j.ijresmar.2015.11.004.

Van Dijk, M. P., Branje, S., Keijsers, L., Hawk, S. T., Hale, W. W., III, \& Meeus, W. (2014). Self-concept clarity across adolescence: Longitudinal associations with open communication with parents and internalizing symptoms. Journal of Youth and Adolescence, 43(11), 18611876.

Van Vugt, M. (2009). Averting the tragedy of the commons using social psychological science to protect the environment. Current Directions in Psychological Science, 18 (3), 169-173.

Verplanken, B., \& Holland, R. W. (2002). Motivated decision making: Effects of activation and self-centrality of values on choices and behavior. Journal of Personality and Social Psychology, 82(3), 434-447. https://doi.org/10.1037//0022-3514.82.3.434.

Welsch, H., \& Kühling, J. (2009). Determinants of pro-environmental consumption: The role of reference groups and routine behavior. Ecological Economics, 69(1), 166-176.

Wernerfelt, B. (1990). Advertising content when brand choice is a signal. Journal of Business, 63(1), 91-98.

Wu, C. -H. (2009). The relationship between attachment style and self-concept clarity: The mediation effect of self-esteem. Personality and Individual Differences, 47(1), 42-46.

Zeithaml, V. A. (1988). Consumer perceptions of price, quality, and value: A means-end model and synthesis of evidence. Journal of Marketing, 52(3), 2-22. 
Fig. 1. Conceptual Framework

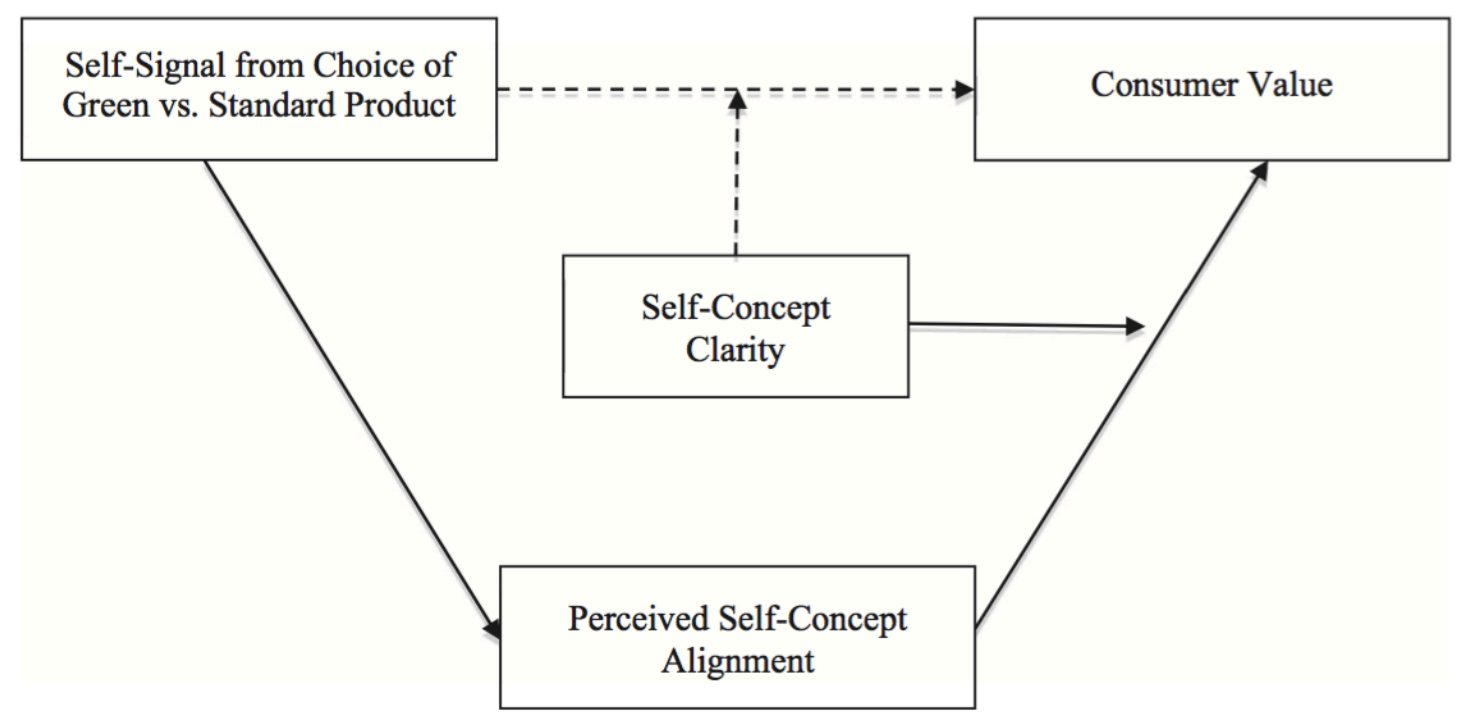

Notes: Relationships depicted by solid arrows are hypothesized to at least partially account for the relationships depicted by dashed arrows. 
High Self-Signal Condition

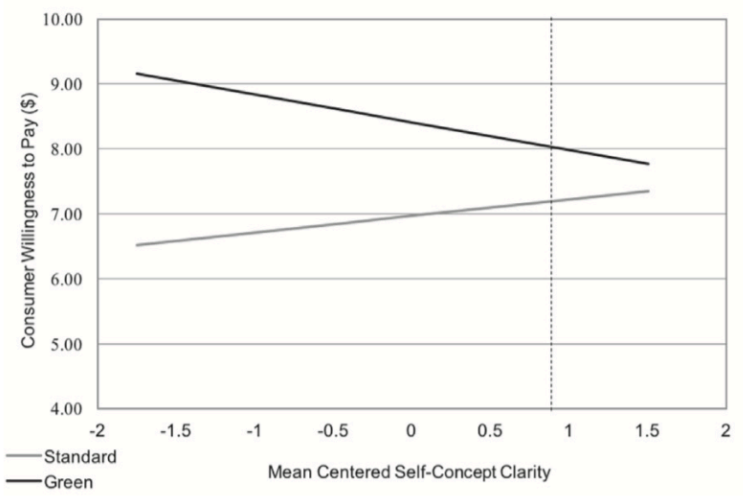

Low Self-Signal Condition

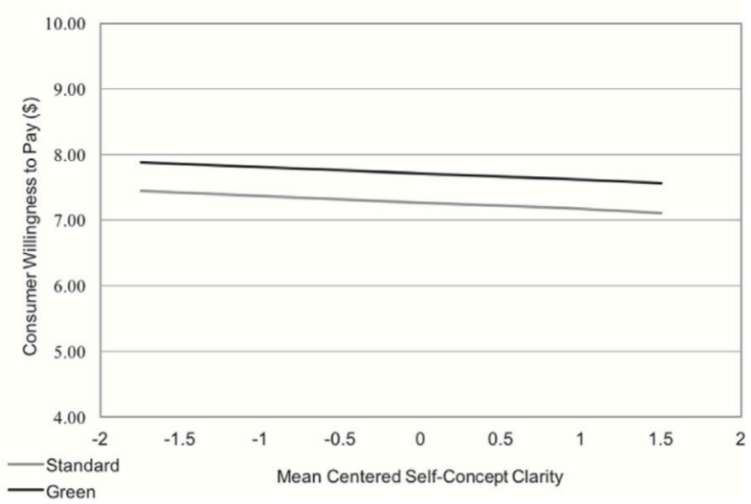

Fig. 2. Consumer willingness to pay for choices of green and standard products for values of self-concept clarity (Study 1a). Notes: The dashed line in the plot for the high self-signal condition represents the Johnson-Neyman-point. The interaction effect in the low self-signal condition is not significant, and this plot serves illustrative purposes only. 


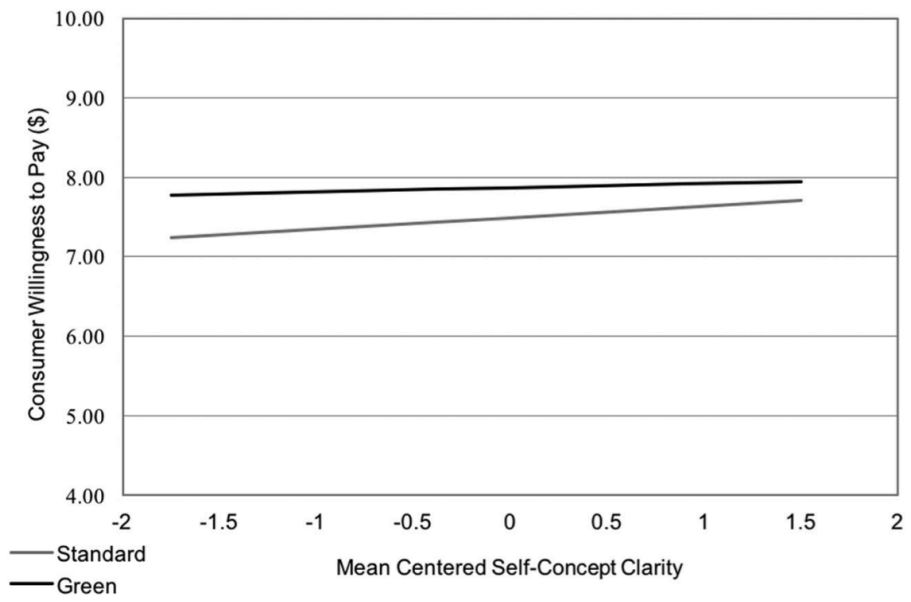

Fig. 3. Other-signal condition results (Study 1a). Notes: The interaction effect in this condition is not significant, and this plots serves illustrative purposes only. 


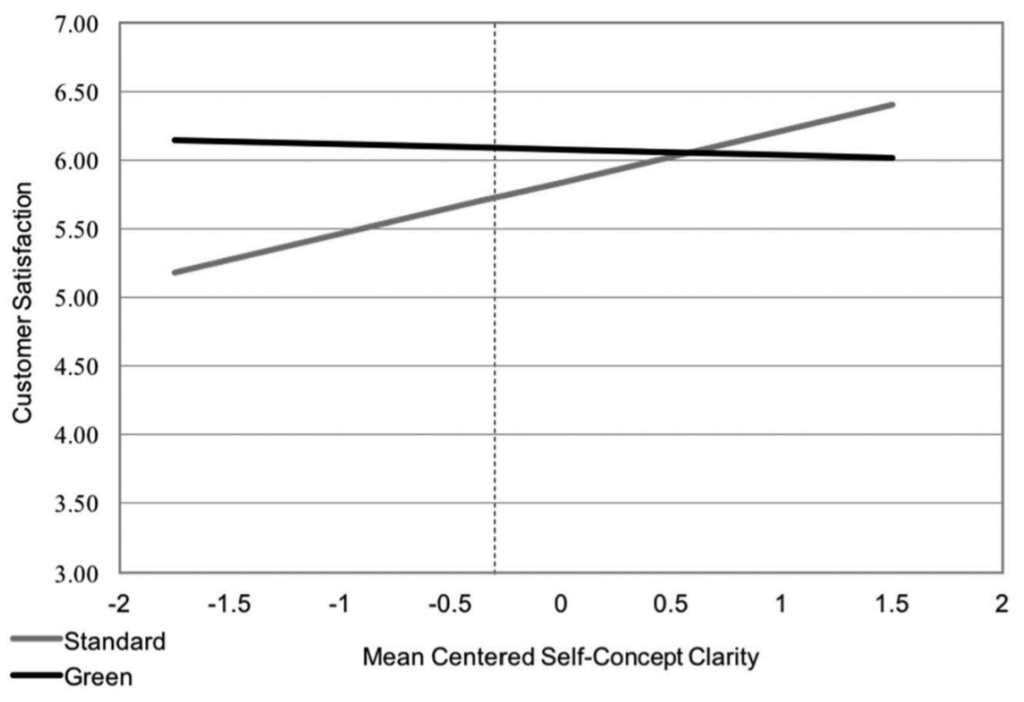

Fig. 4. Results Study 1b. Notes: The dashed line in the plot represents the Johnson-Neyman-point. 


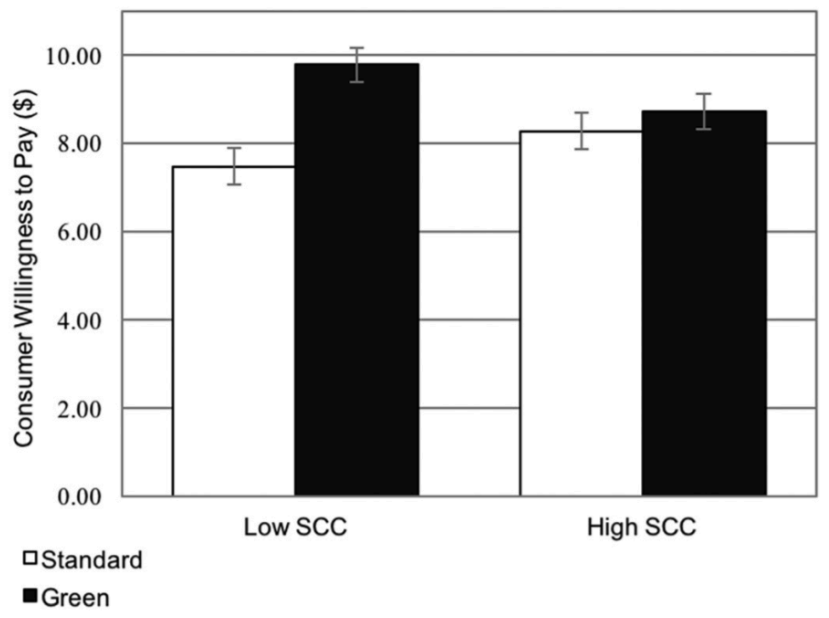

Fig. 5. Study 2 results. Notes: Error bars represent $+/-1$ standard error of the mean. 
High Self-Signal Condition

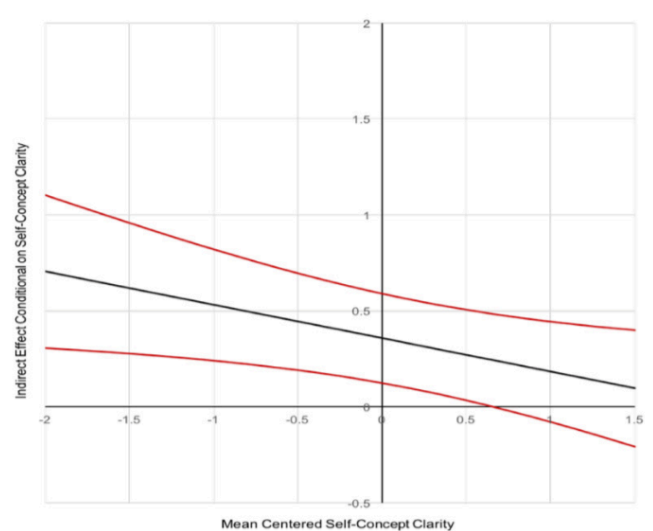

Low Self-Signal Condition

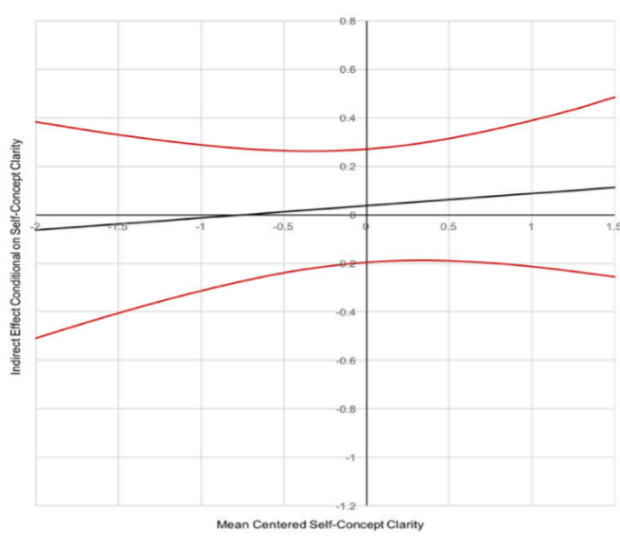

Fig. 6. Regions of significance for indirect self-signaling effect via self-concept alignment on willingness to pay conditional on self-concept clarity (Study 3 ). Notes: The black line represents the conditional indirect effect of positive self-signals through self-concept alignment on willingness to pay at different levels of selfconcept clarity; the red surrounding lines represent 95\%-confidence bands around the estimated effect. The indirect effect in the low self-signal condition is not significant, and this plots serves illustrative purposes only. (For interpretation of the references to color in this figure legend, the reader is referred to the web version of this article.) 


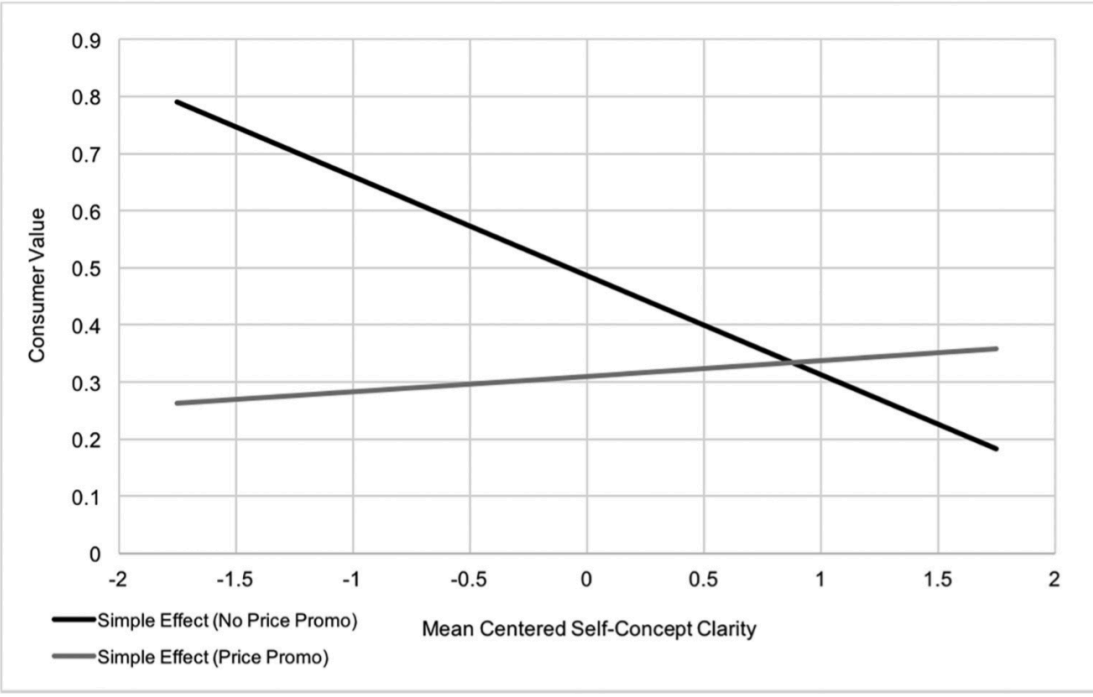

Fig. 7. Simple effect of a choice of a green over a standard product on consumer value (Study 4), 


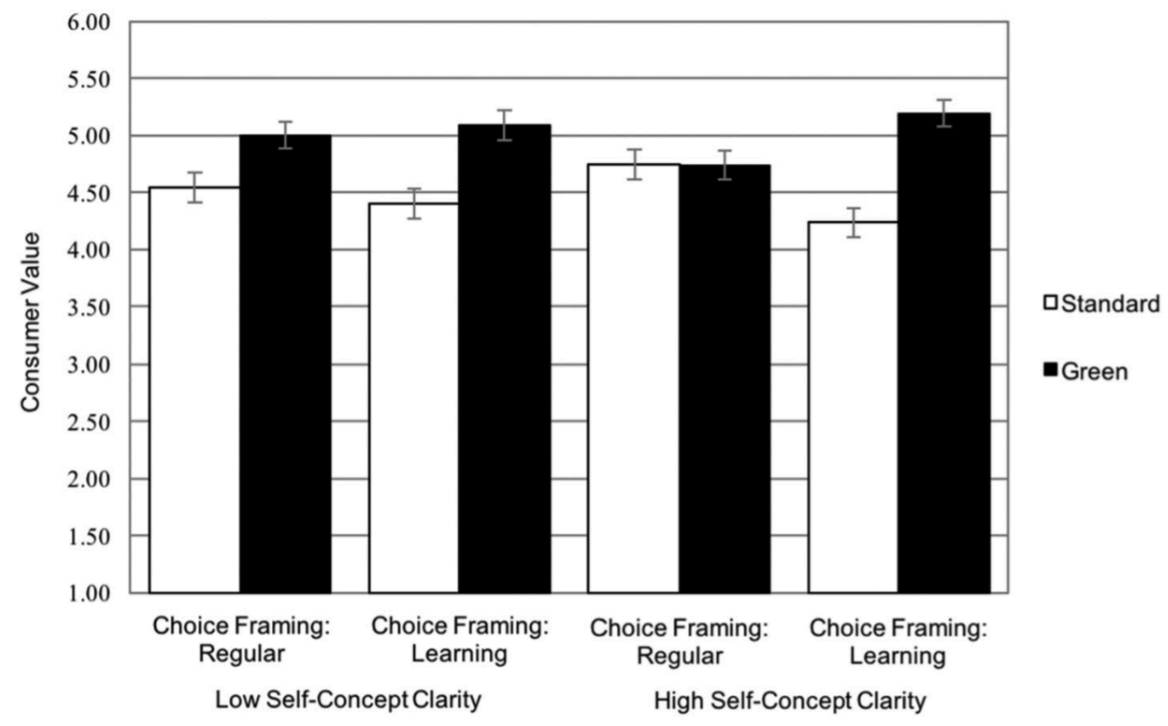

Fig. 8. Study 5 results. Notes: Error bars represent $+/-1$ standard error of the mean. 
Appendix A. Study 1a and Study 3

Please consider the two brands of laundry detergent below. They are both from the same company. The standard brand is on the left. The green brand is on the right.

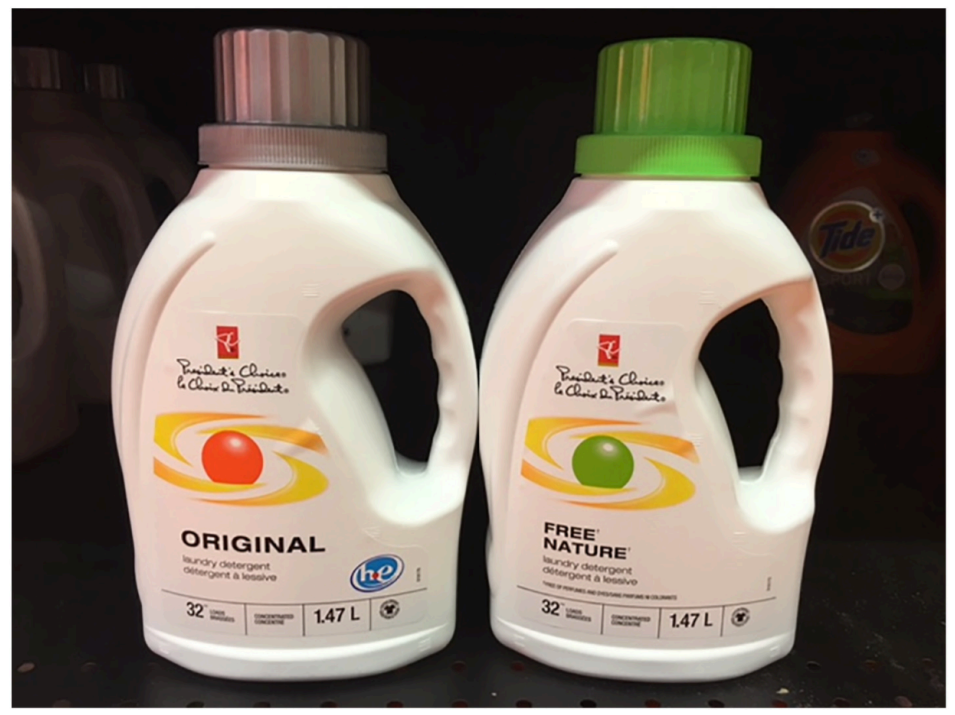

One afternoon, both the standard brand and the green brand are available at the store. You choose the standard [green] brand of laundry detergent. You only made this choice because you are allergic to an ingredient of the other available brand. [You are only making this choice because other shoppers are observing you.]

\section{Appendix B. Study 2: Vignette}

Imagine you are looking to buy laundry detergent at the store.

On some occasions, you choose to buy a standard brand of laundry detergent that you believe is the best quality but contains sulphates, which are widely seen as an unethical ingredient.

On other occasions, you choose to buy a green brand of decent laundry detergent that does not contain sulphates and is there- fore not unethical, but you believe isn't as good a quality as the standard brand.

One afternoon, both the standard brand and the green brand are available at the store. You choose the standard [green] brand.

Appendix C. Study 4 and Study 5: Vignette

Imagine you are looking to buy shampoo at the store.

There is a standard brand of shampoo - one that you believe is the best quality but contains palm oils that have been harvested unethically - in a way that causes deforestation, habitat degradation, and animal cruelty. These shampoos also tend to feel better when you are washing your hair; your hair feels softer and healthier after it has been washed with shampoos that contain palm oil.

There is also a green brand of shampoo - one that you believe to be of decent quality, made without palm 
oil, and that is there- fore produced ethically. Although these shampoos still work, you don't like the feeling of your hair after it has been washed.

One afternoon, both the standard brand and the green brand are available at the store. You choose the standard [green] brand. 